\title{
Testing Installed Propulsion for Shielded Exhaust Configurations
}

\author{
James Bridges ${ }^{*}$, Gary G. Podboy ${ }^{\dagger}$, and Clifford A. Brown* \\ NASA Glenn Research Center, Cleveland, $\mathrm{OH} 44070$
}

\begin{abstract}
Jet-surface interaction (JSI) can be a significant factor in the exhaust noise of installed propulsion systems. Tests to further the understanding and prediction of the acoustic impacts of JSI have been described. While there were many objectives for the test, the overall objective was to prepare for a future test validating the design of a low-noise, lowboom supersonic commercial airliner. In this paper we explore design requirements for a partial aircraft model to be used in subscale acoustic testing, especially focusing on the amount of aircraft body that must be included to produce the acoustic environment between propulsion exhaust system and observer. We document the dual-stream jets, both nozzle and flow conditions, which were tested to extend JSI acoustic modeling from simple singlestream jets to realistic dual-stream exhaust nozzles. Sample observations are provided of changes to far-field sound as surface geometry and flow conditions were varied. Initial measurements are presented for integrating the propulsion on the airframe for a supersonic airliner with simulated airframe geometries and nozzles. Acoustic impacts of installation were modest, resulting in variations of less than 3 EPNdB in most configurations.
\end{abstract}

\section{Nomenclature}

Al core nozzle area

A2 fan/bypass nozzle area

Ae total nozzle area equivalent to a single stream

beta potential core length from outer nozzle lip

$c_{j} \quad$ speed of sound, jet stream

$c_{\infty} \quad$ speed of sound, ambient

$D_{1, i} \quad$ core nozzle inner diameter

$D_{1, o} \quad$ core nozzle outer diameter

$D_{2, i} \quad$ bypass nozzle inner diameter

$D_{2, o} \quad$ bypass nozzle outer diameter

$D_{e} \quad$ total nozzle diameter equivalent to a single stream

$h_{E} \quad$ surface standoff distance from lipline

$h_{E}{ }^{*} \quad$ surface standoff distance from minimum radius of plume

JSI Jet-Surface Interaction

$M \quad$ gas Mach number, $u_{j} / c_{j}$

$M a \quad$ acoustic Mach number, $u_{j} / c_{\infty}$

$P S D$ power spectral density

$N P R b$ bypass nozzle pressure ratio

$N P R_{c} \quad$ core nozzle pressure ratio

$T_{s} R \quad$ static temperature ratio

$T T R b$ bypass nozzle total temperature ratio

$T T R_{c} \quad$ core nozzle total temperature ratio

$u_{j} \quad$ jet velocity

$x_{E} \quad$ surface length, as measured from outer nozzle lip

\footnotetext{
* Acoustics Branch, MS 54-3; AIAA Associate Fellow

$\dagger$ Acoustics Branch, MS 54-3; AIAA Member

$\$$ Acoustics Branch, MS 54-3; AIAA Senior Member
} 


\section{Introduction}

The quest to design a supersonic airliner that can meet conventional airport noise regulations, such as the one exemplified in Figure 1, requires evaluation of exhaust noise including the acoustic impacts of the installation of the propulsion system with the airframe. Since 2010 NASA researchers have been exploring the noise produced by the interaction of jet plumes with surfaces, generically called the jet-surface interaction or JSI problem. ${ }^{1}$ This work has focused on single-stream jets from a simple conic nozzle interacting with a simple, semi-infinite surface. These experiments have taught the basic mechanisms of the dipole trailing edge source and of the acoustic effects of shielding and reflection of jet mixing noise. Significant effort has been put into creating empirical models that predict these acoustic effects for a range of single-stream jet flows and surface geometries., ${ }^{2,3}$ The next steps in increasing fidelity are to consider multi-stream jets from plugged separate flow nozzles, surfaces that are not semiinfinite in span, the presence of flight stream around the jet and surface, and aero features such as lift of the body on the plume. The test being reported here, called the 'JSI1044' test, addresses all but the flight stream aspects; there is no flight stream and hence no effects from a lifting body. Requirements for acoustically simulating installed propulsion using a jet rig were explored, with eye towards testing in a flight stream in the near future.

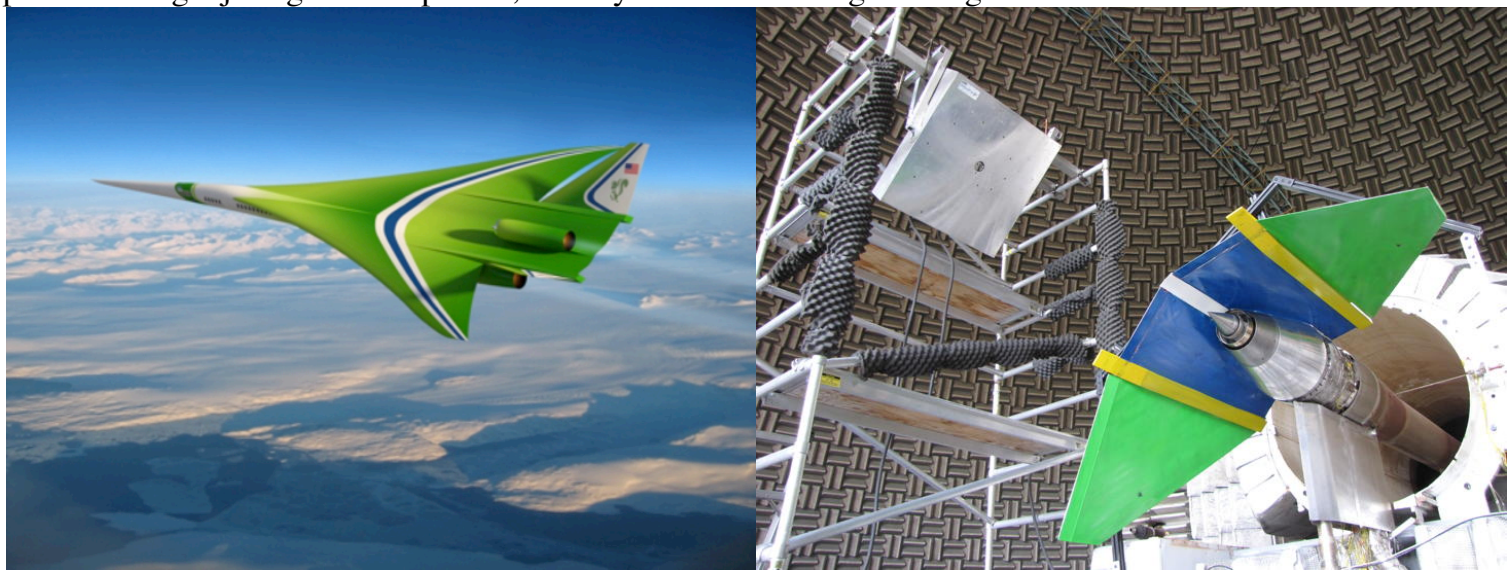

Figure 1 Conceptual supersonic airliner (left) and scaled acoustic model for integrated propulsion noise testing in NASA Aero-Acoustic Propulsion Laboratory (right).

Several challenges arise in trying to make acoustic measurements in scale-model tests for installed propulsion. Before JSI testing can include flight, test hardware must be designed to withstand the aerodynamic loads of the flight stream. The finite dimensions of a tunnel, enclosed or open jet, limit the size of the surface. If the surface extends beyond the flight stream edge it will produce additional background noise by its interaction with the flight stream shear layer. If the entire vehicle is represented, such as in the Hybrid Wing Body (HWB) test in Langley's $14 \times 22$ tunnel, ${ }^{4}$ then the scale factor of the model is often very large and the model-scale frequencies of interest are exceedingly high. If a partial vehicle is used, such as in initial explorations of the HWB jet noise problem, ${ }^{5}$ the scale factor can be more modest, but it is critical that all aspects of the vehicle that impact the sound generation and propagation be properly represented. This is especially critical when the airframe provides significant shielding, as in the case of top-mounted engines on a large planform body. This was the configuration of the HWB, and of the $\mathrm{N}+2$ supersonic airliner that is of current interest. ${ }^{6}$ For exhaust noise the aircraft body represents a surface stretching essentially infinitely far upstream, which is a challenge for experimental rigs.

Earlier static tests demonstrated the importance of projecting the surface far forward of the nozzle to avoid noise refracting around the forward edge of the surface. In an open tunnel this edge will be somewhere inside the tunnel nozzle. The larger the surface, the higher aero loads it will have to withstand and more rigid support structure is required. In addition, previous studies have found that when surfaces internally bisect a round nozzle the surface undergoes aeroelastic loading that often leads to failure of its support. From all these known considerations (and probably some not yet discovered) it is critical to first understand the acoustic requirements for a surface in the facility without flight and to find ways to eliminate unwanted aeroelastic behavior when the model is placed in ambient flight flow. To this end, a static test program was pursued where surfaces could be easily fabricated and simply attached. These surfaces included flat panels reminiscent of those tested in previous JSI tests, and more complicated ones with geometries resembling the N+2 supersonic aircraft. The former were used to tie the multistream exhaust cases back to the previous work while the latter gave insight into the acoustic effects anticipated with the more realistic model to be tested in the future. 
One practical aspect of the airframe representation that is very troubling is the way a flat surface must integrate with the cylindrical jet rig upstream of the nozzle. Jet rigs are much larger in diameter than nacelles, so even when the propulsion is a podded engine the rig will intersect with the body when the nozzle is properly located relative to the airframe. Previous JSI testing showed the importance of extending the surface far forward of the nozzle, at least for some flow conditions, but this will complicate the fabrication and attachment of the airframe to the rig. If the airframe is to be allowed to move relative to the nozzle then the changing intersection of the rig/surface becomes a mechanical challenge. An alternative concept is to separate the surface extending upstream from the one near the nozzle so that the upstream surface can be located on top of the rig while the surface interacting with the plume need only interface with the downstream portion of the nozzle. It is not clear that this is satisfactory acoustically; this concept, called the 'biplane', will be explored in this paper.

In this static test the extension of the JSI acoustic database from single-stream to multi-stream jets with more complicated nozzle was done using a simple surface like that in the earlier JSI tests. The approach is to treat these flows as having an unknown equivalence to the single-stream jets already studied. ${ }^{7}$ Equivalence to four parameters of the single-stream jet was sought: equivalent nozzle exit plane, lip line, velocity, and temperature. The latter two may be the fully mixed values for the multi-stream jet or the outer stream values. The exit plane and nozzle lipline may relate to the minimum of the jet plume which occurs near the end of the plug tip at the matched-area diameter, or one of the physical nozzle lips. These were determined by acquiring data, especially phased array measurements of source location as a function of frequency, from separate flow nozzles with the various streams being run at the same temperatures and velocities, which should equate to the simple jet flows tested earlier. ${ }^{8}$ When a match is found between the acoustic noise generated in the multi- and single-stream jets, the offset in axial and standoff positions will give the equivalence in nozzle exit and lipline. Matching acoustic results at the same equivalent geometric parameters but with the multi-stream nozzles running different flow conditions will establish a relationship between the single-jet flow parameters and the multi-stream flows. A companion paper ${ }^{9}$ will present the results of this modeling effort.

While there were many objectives for the JSI1044 test, the overall objective was to prepare for a future test validating the design of a low-noise, low-boom supersonic commercial airliner. The surrogate airframe was the N+2-era design, model 1044-3, created by Lockheed-Martin and General Electric under contract to NASA. More details on this design can be found in Reference [6]. The JSI1044 test $(i)$ established the requirements for future test hardware, (ii) provided data to update the acoustic models of JSI to handle the multi-stream, finite-span surfaces, (iii) provided insight into test procedures for installed exhaust noise testing, and (iv) made initial acoustic measurements of the installation effects for a representative airframe geometry integrated with the realistic propulsion exhaust system. This report provides an overview of these aspects of this test.

\section{Facility}

The test was conducted in the NASA Glenn Research Center Aero-Acoustic Propulsion Laboratory (AAPL). The AAPL is a 65-foot radius anechoic geodesic hemispherical dome. Acoustic wedges cover the walls of the dome and the floor area of the acoustic arena surrounding the jet rigs.

The Nozzle Aeroacoustic Test Rig (NATR) is an open tunnel (free jet) located at the center of the AAPL. The NATR provides the airflow for the test article and a flight simulation capability. The centerline of the free jet is 10 feet above the floor. This arrangement can produce Mach numbers in the free jet up to 0.35 , although this test was static, i.e. no tunnel flow. An acoustically treated wall separates the NATR from the section of the building which does not have acoustic treatment on the floor, preventing unwanted reflections from both the untreated floor area and adjacent test equipment.

At the downstream end of the NATR is the Dual Flow Jet Exit Rig (DFJER). The DFJER is the structure through which heated air is delivered from the facility compressed air system to the test article. The inner air stream can be heated using a natural gas combustor to $1200^{\circ} \mathrm{F}$, with pressure ratios beyond 4 . The second air stream can be heated using a heat exchanger up to $300^{\circ} \mathrm{F}$ and can deliver air at pressure ratios beyond 4 . The combined mass flow of the two streams is up to $30 \mathrm{lbm} / \mathrm{sec}$.

The rig was instrumented to record total temperature, total pressure at the charging station on both streams. In addition, mass flow rates were recorded using unchoked venturi meters. In operation, the rig flow conditions are set according to preset pressure and temperature ratios, with real-time monitoring to assure that the flow stays within $0.5 \%$ cumulative of the desired conditions during data acquisition.

Ambient conditions were also recorded on the facility computer. Relative humidity and temperature were recorded both at 10 feet above the floor near the NATR and at the top-most region of the overhead microphone 
array, located roughly 60 feet above the floor. In addition to the standard rig flow documentation, the position of the actuated surface, as measured by the actuation system, was also recorded.

\section{Model Hardware}

\section{A. Nozzle definitions}

The engine that conceptually drives the aircraft being studied is a variable cycle engine with two fan streams. In the exhaust systems being tested, the core and first fan stream are internally mixed to produce a primary exhaust stream, with the tip fan flow being externally mixed. Two types of exhaust systems were used in this test: a conventional separate flow nozzle with the hot primary flow on the innermost stream and the tip fan flow being on the outermost, and an inverted velocity profile nozzle in which the tip fan flow was ducted to the innermost nozzle. Both exhaust systems had a large plug to reduce the boattail angle on the engine nacelle.

For the conventional exhaust system two separate flow nozzles from previous tests, ${ }^{10}$ named $\mathrm{C} 1$ and $\mathrm{C} 3$, were used, providing two different area ratios. These nozzles were designed to have three separate coannular streams but only the innermost two streams were operated here with the third stream nozzle removed to allow closer fitting of the surface when positioned at the nozzle lip. Critical nozzle dimensions for the conventional separate flow nozzles are given in Table 1 with sketches of the two nozzles in Figure 2.

Table 1 Nozzle ID, inner and outer diameters, stream areas, area ratios, and equivalent diameters.

\begin{tabular}{|c|c|c|c|c|c|c|c|c|c|}
\hline \hline Nozzle ID & $D_{l, i}$ & $D_{l, o}$ & $A_{1}$ & $D_{2, i}$ & $D_{2, o}$ & $A_{2}$ & $A_{2} / A_{1}$ & $D e_{1}$ & $D e_{1+2}$ \\
\hline \hline $\mathrm{C} 1$ & 3.674 & 5.187 & 10.529 & 7.37 & 9.373 & 26.339 & 2.50 & 3.66 & 6.85 \\
\hline $\mathrm{C} 3$ & 3.674 & 5.187 & 10.529 & 8.63 & 9.373 & 10.506 & 1.00 & 3.66 & 5.18 \\
\hline
\end{tabular}

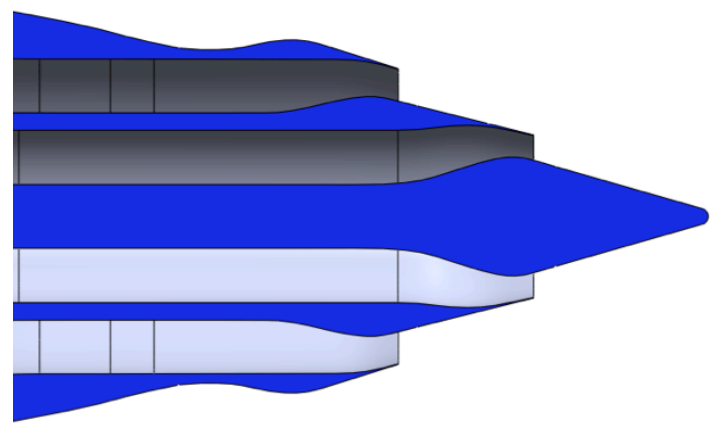

(a)

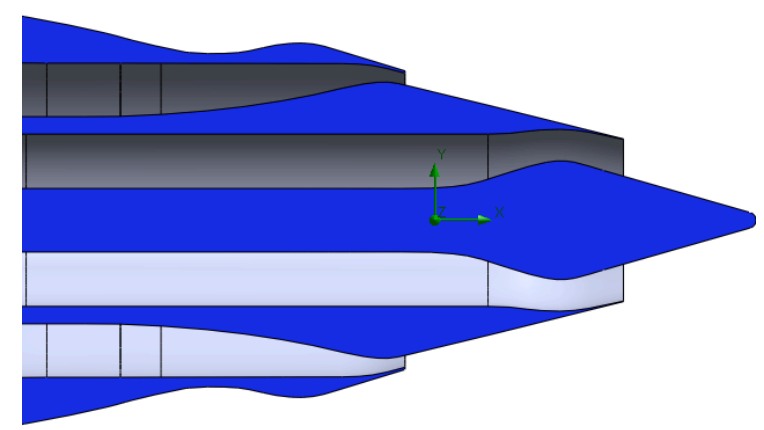

(b)

Figure 2 Internal profiles of dual-stream nozzles. (a) C1, (b) C3.

The inverted velocity profile nozzle was an exhaust system designed by General Electric as part of their NASA N+2 study. Flow lines and areas of the original nozzles are proprietary, but the general design is shown in Figure 3, which is from the Lockheed Martin/General Electric report. ${ }^{6}$ The nozzle features a large plug, a small inner annulus for cold flow, and a $180^{\circ}$ annulus providing a cold buffer flow, and is designated SL2B. When installed, the buffer flow was configured toward the ground (away from the surface for underwing installation, towards the surface for overwing installation).

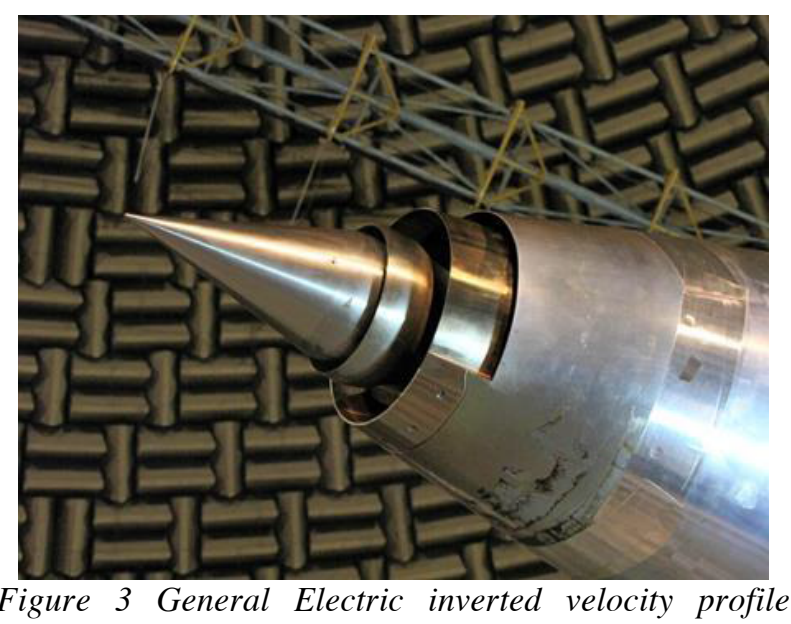
nozzle, SL2B. 


\section{B. Flow conditions and setpoint definitions}

For the objective of exploring the acoustic efficacy of the biplane configuration the rig was run with unheated flows, with pressure matched between the nozzle streams, to emulate a single-stream jet, albeit one with a large external plug. These conditions have been measured in previous JSI tests ${ }^{1}$ (on a simple nozzle without an external plug) and allowed quick data acquisition and configuration changes without waiting for the rig to cool. These conditions are shown in Table 2. Note that changing the setpoints by adding the bypass stream changed the geometry of the flow, altering the effective lipline along with the effective diameter. This series of data also allowed the comparison of external plug nozzles to the simple nozzles previously used in the JSI database.

To extend the JSI database to dual-stream plumes, a matrix of flows with hot core/cold fan streams were used; this matrix has been tabulated in Table 3. The setpoints were based on nozzle pressure ratio (NPR) and nozzle temperature ratio $(N T R)$, and result in different fully mixed conditions for the two dual-stream nozzles as they have different area ratios. These points were selected to provide an array of expected potential core lengths and turbulence distributions based on previous analysis of PIV data. ${ }^{7}$ In that analysis the potential core length was found to scale with the fully mixed flow conditions while the turbulent velocity magnitude scaled by core velocity. Figure 4 shows the fully mixed acoustic Mach numbers and the predicted potential core lengths for all the setpoints that were used in the tests with variable flat surface.

Finally, when the LM1044-specific configuration was run with the General Electric inverted velocity profile nozzle, cycle points were picked that correspond to engine conditions reasonable for the proposed concept aircraft. The flow conditions used in this test are tabulated in Table 4.

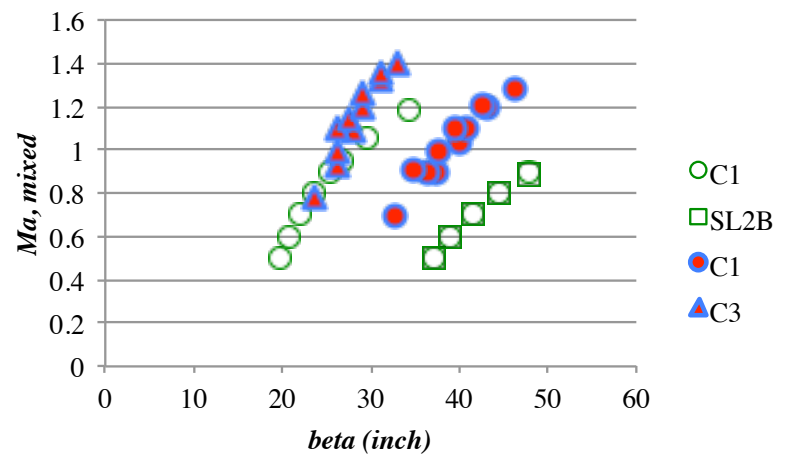

Table 2 Definitions of single-stream setpoints on the $C 1$ nozzle. $N P R_{b}$ matches $N P R_{c}$ when outer stream is active.

\begin{tabular}{|c|c|c|c|c|c|}
\hline \hline Setpoint & $N P R_{c}$ & $N T R_{c}$ & $N P R_{b}$ & $M a$ & $M$ \\
\hline \hline 300 & 1.200 & 1 & 1 & 0.50 & 0.52 \\
\hline 330 & 1.200 & 1 & 1.200 & 0.50 & 0.52 \\
\hline 500 & 1.435 & 1 & 1 & 0.70 & 0.74 \\
\hline 550 & 1.435 & 1 & 1.435 & 0.70 & 0.74 \\
\hline 700 & 1.856 & 1 & 1 & 0.90 & 0.98 \\
\hline 770 & 1.856 & 1 & 1.856 & 0.90 & 0.98 \\
\hline 9010 & 3.183 & 1 & 1 & 1.19 & 1.40 \\
\hline
\end{tabular}

Table 3 Matrix of setpoints for conventional dualstream flows on nozzles $C 1$ and $C 3$.

\begin{tabular}{|c|c|c|c|c|}
\hline \hline Setpoint & $N P R_{c}$ & $N T R_{c}$ & $N P R_{b}$ & $N T R_{b}$ \\
\hline \hline 1312 & 1.3 & 3 & 1.22 & 1.25 \\
\hline 1316 & 1.3 & 3 & 1.58 & 1.25 \\
\hline 1518 & 1.5 & 3 & 1.8 & 1.25 \\
\hline 1813 & 1.8 & 3 & 1.25 & 1.25 \\
\hline 1815 & 1.8 & 3 & 1.5 & 1.25 \\
\hline 1818 & 1.8 & 3 & 1.8 & 1.25 \\
\hline 2116 & 2.1 & 3 & 1.6 & 1.25 \\
\hline 2120 & 2.1 & 3 & 2.0 & 1.25 \\
\hline 2323 & 2.3 & 3 & 2.3 & 1.25 \\
\hline
\end{tabular}

Table 4 Matrix of setpoints for inverted velocity profile flows on nozzle SL2B.

Figure 4 Derived flow parameters of setpoints used in test of flat surface: ideally mixed acoustic Mach number vs potential core length, beta. Single-stream flows are given by open symbols; dual-stream flows are given by filled symbols.

\begin{tabular}{|c|c|c|c|c|}
\hline \hline Setpoint & $\begin{array}{c}\text { NPR } \\
\text { primary }\end{array}$ & $\begin{array}{c}\text { NTR } \\
\text { primary }\end{array}$ & $\begin{array}{c}\text { NPR } \\
\text { inner }\end{array}$ & $\begin{array}{c}\text { NTR } \\
\text { inner }\end{array}$ \\
\hline \hline 3360 & 2.147 & 1.935 & 1.780 & 1.259 \\
\hline 3350 & 2.014 & 1.881 & 1.780 & 1.259 \\
\hline
\end{tabular}

\section{Surface Configurations}

The surfaces tested in this jet-surface interaction test fell under two broad categories: generic single-planes, herein call 'flat configurations', and a planform simulation of the aft deck of the Lockheed Martin N+2 concept vehicle, designated 'JSI 1044 configurations'. The flat configurations are intended to represent generic surfaces and tie this data back to earlier datasets featuring simple single-stream nozzle flows. Only the flat surface configurations had variable geometry. Since the far-field microphone array was located in the ceiling of the chamber in a polar arc plane roughly $25^{\circ}$ from vertical, the surfaces had to be tilted at this angle to present a surface normal to the microphones. 


\section{Flat configurations}

The flat surface configurations, shown in Figure 5, consist of a fixed and an actuated surface. The fixed surface, referred to as the 'biplane', was a plate located off the rig while the actuated surface had a fitted 'cutout' that nestled against the nozzle exterior when the actuated surface was at its smallest standoff. The biplane surface essentially blocked noise coming from upstream of the actuated surface from reaching the microphones. The structural supports were constructed of 1.5" 8020 T-slot framing and joining hardware, a few pipe stands, clamps, and actuators. The surfaces themselves were $1 / 2$ " thick aluminum honeycomb panels with added edges as required. The edges of the sheets were covered with

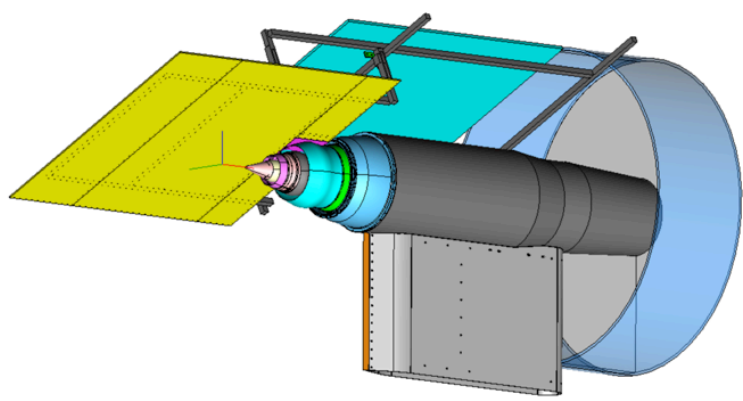

Figure 5 Flat surface hardware in shielding orientation to overhead microphones. aluminum tape except for the downstream edge of the actuated surface which was fitted with a $45^{\circ}$ bevel to be consistent with previous JSI test designs. A printed plastic filler piece was employed to fit tightly around the external surface of the nozzles when the surface was tangent to the nozzle lip. For the portion of the test that considered the span of the surface to be effectively infinite, the span of the surface was 48", which was found to be indistinguishable from a surface much wider in previous testing. A chart of the surface dimensions tested is given in Figure 6. The range of lengths $x_{E}$ tested can be juxtaposed to the range of potential cores of the setpoints tested, shown in Figure 4, to understand the sizes of the surface configurations relative to the jet flows.

One complicating aspect of testing an externally plugged nozzle is that the plume diameter shrinks going downstream as it passes over the plug, reaching a minimum somewhere just upstream of the plug tip. So should the standoff $h_{E}$ be measured from the nozzle lip, as it has been for a simple nozzle? Or should it be measured from the minimum plume radius? This is most important in modeling the trailing edge dipole, which depends on the location of the trailing edge relative to the shear layer. In Figure 6, both the lipline standoff, $h_{E}$, and a second standoff, $h_{E}{ }^{*}$, is tabulated, this standoff being the position of the surface relative to the expected minimum of the plume, $D e / 2$.

The fixed surface (biplane) and framework were attached across the face of NATR with additional

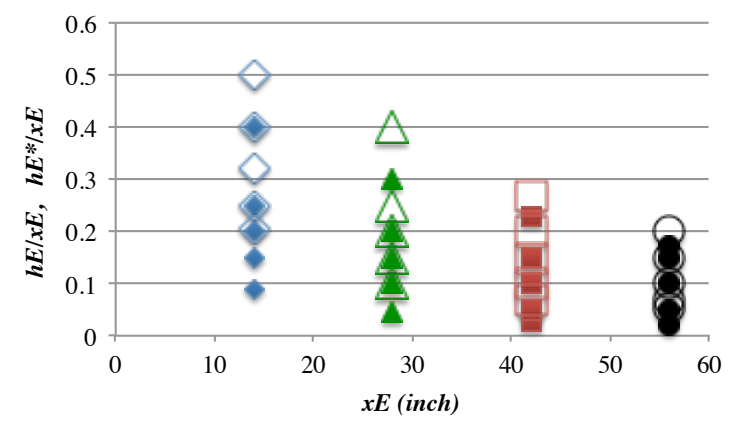

Figure 6 Lengths and standoffs of flat surfaces tested. Closed symbols are standoffs $h_{E}$ as measured from nozzle lip, open symbols are standoffs $h_{E}{ }^{*}$ as measured from the radius of the fully mixed jet diameter. support provided by tripods from the ground. The frame supported the biplane surface on top of the jet rig, allowing a 48" wide biplane to just fit into the exit of the NATR. The actuated surface could move between the limits where it touched the nozzle and touched the biplane, a distance of 8.5", as shown in Figure 7.

Many variations in the biplane were tested, but the most important configurations are shown in Figure 8. In addition to the bare configuration and configuration with only the actuated surface (no biplane surface), two lengths of biplane surface were used, one 48" long and one 21 " long, both 48 " wide. These two surfaces were positioned with their downstream edges either aligned with the nozzle exit plane, which gave an overlap with the actuated surface of 7.5", or with zero overlap with the actuated surface. Not shown are configurations where the actuated surface was removed to determine if the biplane was interfering with upstream microphone measurements by comparing with the bare configuration. 


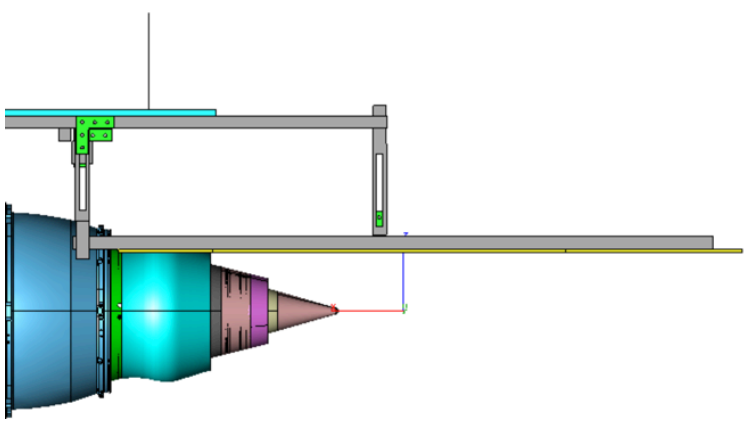

(a)

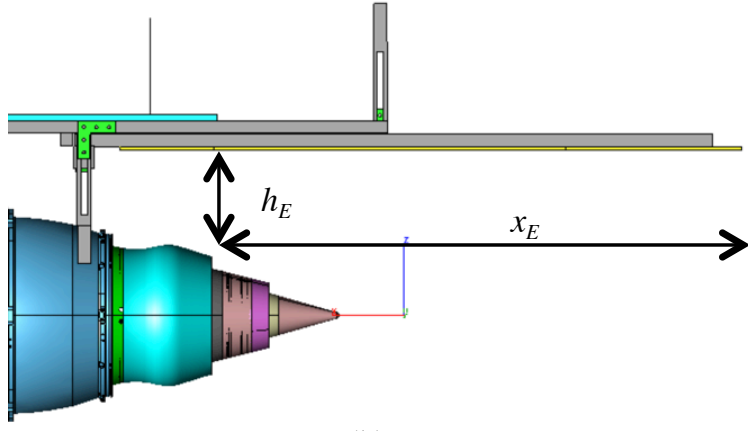

(b)

Figure 7 JSI Flat configuration, showing actuated surface movements on C1 nozzle. Actuated surface of reference length $x_{E}$ at standoff $(a) h_{E}=0(b), h_{E}=8.5$ ".

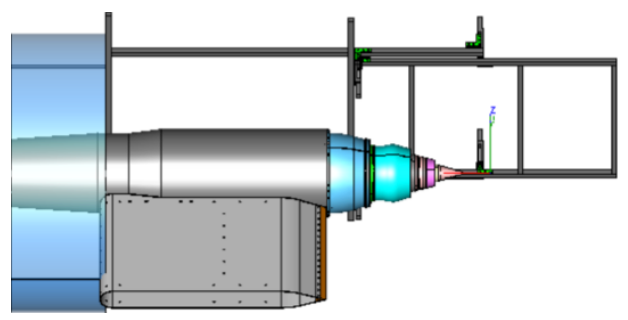

Frame only, no surfaces

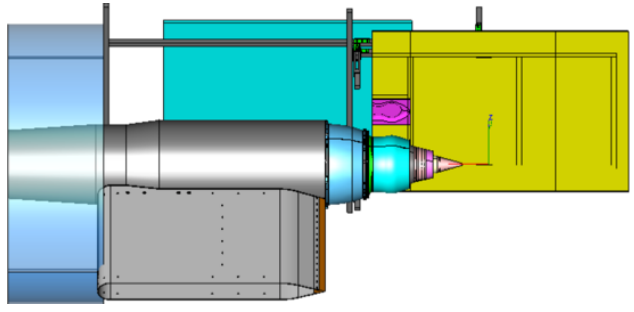

Long (48”) biplane surface, max overlap (7.5”)

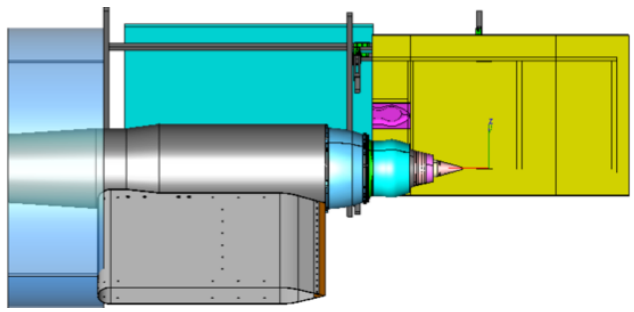

Long (48") biplane surface, no overlap (0")

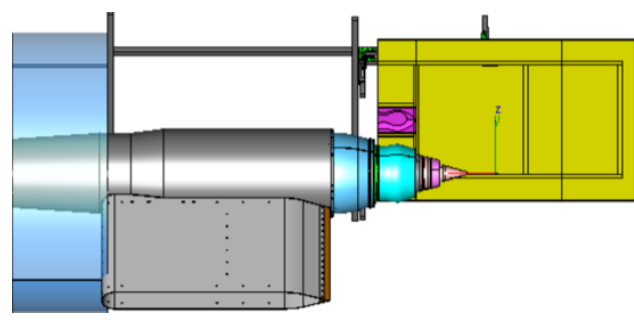

Actuated surface only

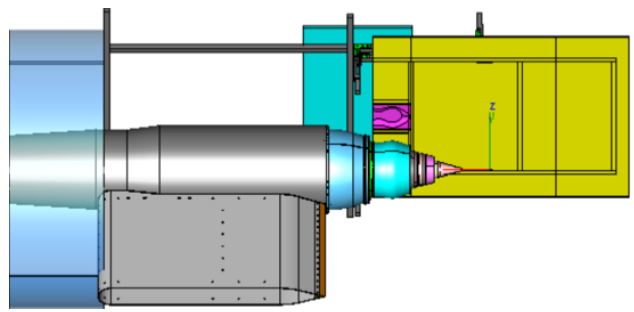

Short (21") biplane surface, max overlap (7.5”)

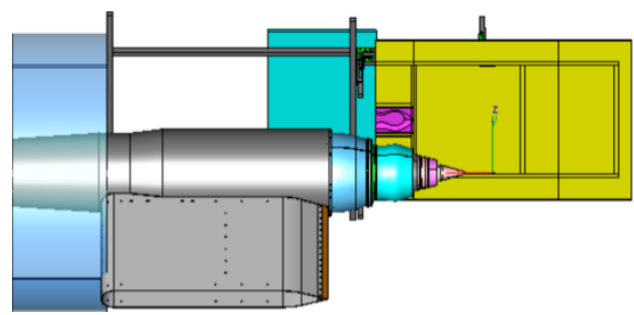

Short (21") biplane surface, no overlap (0")

Figure 8 Biplane surface configurations as viewed from underneath the rig.

\section{JSI 1044 configurations}

This test was motivated by the need to predict and validate the exhaust noise of installed propulsion for a lowboom supersonic commercial airliner. A candidate vehicle, engine, and exhaust nozzle has been identified in previous studies and tests of isolated nozzles. The empirical models for JSI acoustic impacts, created for simple geometries such as that described above, will be employed to predict the installed noise of the aircraft. A validation of these models as applied to more complicated airframe configurations is required, along with experience in designing a partial aircraft model that simulates the flow and acoustic environment of the nozzle as installed on an actual vehicle. Portions of the aft end of the Lockheed Martin $1044 \mathrm{~N}+2$ supersonic aircraft, including the aft deck, pylons, and tail fins, were scaled for the jet rig, properly locating the nozzle relative to the surfaces. These surfaces were only used with the inverted velocity profile nozzle. 
There are two JSI 1044 configurations, one representing the center engine installation, and one representing the outboard engine installation, as shown in Figure 9. There was no actuation of these surfaces. The main surface, representing the aft deck of the aircraft, was cut out to closely fit the outer contours of the jet rig. Each configuration was angled to different azimuthal orientations to produce the required sideline and flyover observer angles encountered during simulated noise certification flights. The center engine installation is a top-mount, so the surface is in a shielding orientation, and by symmetry only needed to be tested at $0^{\circ}$ (flyover) and $60^{\circ}$ (sideline) azimuthal rotations (Figure 10). The outboard engine installation is an underwing mount, so the surfaces are in a reflecting orientation, and because the surfaces are not symmetric three azimuthal orientations were measured (Figure 11). The outboard engine installation was a reflecting orientation; hence the biplane surface was required.

\section{Instrumentation}

\section{A. Far-field acoustics}

An overhead 24-microphone arc array was used for measuring far-field spectral directivity. The arc spans the ceiling of the AAPL and is roughly centered on the nozzle exit with a radius of 45 feet. The plane of the arc is $25^{\circ}$ from vertical. The $1 / 4 "$ B\&K (4939) freefield microphones were located on the ends of $\mathrm{B} \& \mathrm{~K}$ microphone holders (UA-1588) with a $45^{\circ}$ angle to the holder to minimize reflections. The microphones themselves are pointed at the nozzle exit and are operated without gridcap to optimize frequency response. 1/4" B\&K preamps (2670) are used along with the Nexus power supply/signal conditioner. Ten seconds of data were acquired at $200 \mathrm{kHz}$ for each reading on a DataMAX acquisition computer. End-to-end in situ calibrations of the microphones were performed weekly using a B\&K 4228 pistonphone. Acoustic data were processed to account for individual microphone sensitivities and spectral characteristics, losses due to atmospheric attenuation, and spherical spreading. Far-field acoustic data presented in the paper are power spectral density normalized to a 1-foot sphere with no atmospheric attenuation.

\section{B. Phased Array}

The phased array, model Array48 from OptiNav, Inc, was used for portions of this test.

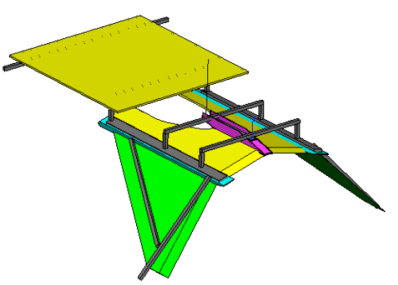

(a)

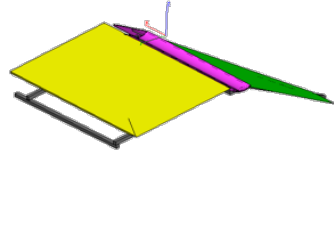

(b)
Figure 9 JSI 1044 Center (a) and Outboard (b) surface configurations.
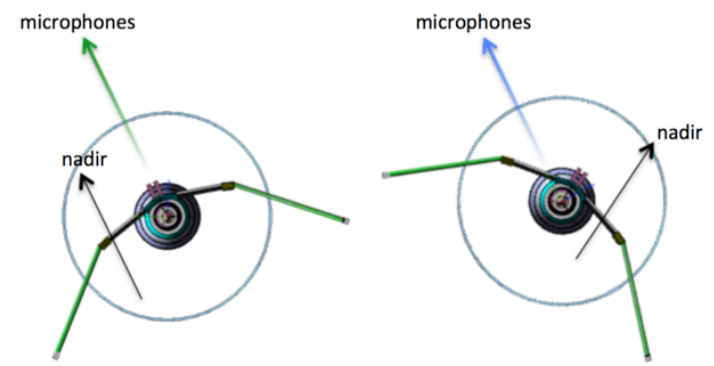

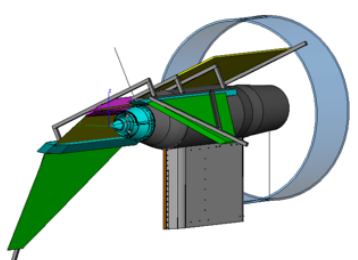

(a)

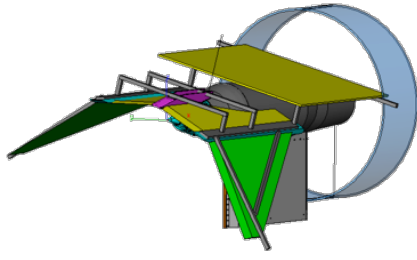

(b)
Figure 10 JSI 1044 Center configuration, mounted on HFJER, in $0^{\circ}(a)$ and $60^{\circ}(b)$ orientations. Nadir is direction to ground for aircraft in flight.
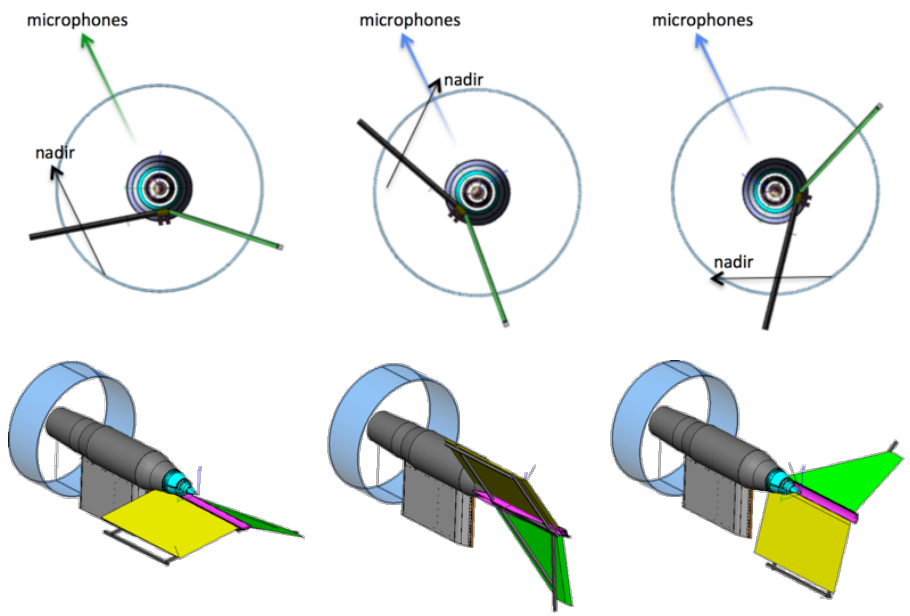

(a)

(b)

(c)

Figure 11 JSI1044 Outboard configuration, mounted on HFJER, in $0^{\circ}(a),+60^{\circ}(b)$, and $-60^{\circ}(\mathrm{c})$ orientations. Nadir is direction to ground for aircraft in flight. 
The data was processed using conventional beamforming. The phased array was used to identify noise source locations for both baseline (no surface) and surface configurations. It was especially useful in identifying any unexpected source or reflection. The phased array was positioned at a polar angle of roughly $90^{\circ}$ to the nozzle plug tip, at a distance of $2 \mathrm{~m}$ from the jet centerline, and approximately in the plane of the overhead microphones. Commercial scaffolding was used to mount the array. Figure 12 shows the position of the phased array and overhead microphone array relative to the test hardware.

\section{Results}

\section{A. Biplane explorations}

As mentioned in the description of the surface hardware, the point of the biplane surface was to continue the acoustic shielding surface forward without having to fit the surface around the contours of the jet rig. Many configurations of the biplane were tried (different widths and lengths, different standoffs from the rig, and various amounts of overlap with the actuated surface) to determine what configurations would allow noise from the nozzle to be blocked from 'leaking around' the upstream edge of the actuated surface (see Figure 8). For brevity only a few comparisons will be shown here to summarize the

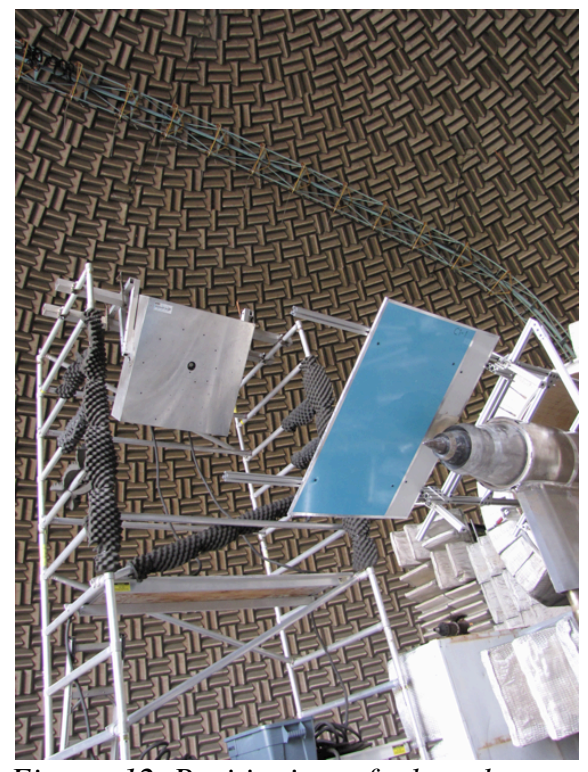

Figure 12 Positioning of phased array and overhead microphone arc array to JSI 1044 hardware. findings. To start, it would be reasonable to believe that the larger the biplane surface the more complete the shielding would be. Also, the greater the overlap the less sound would 'leak' between the biplane and the actuated surface.

The first comparison is between the longest biplane (48" long) and a far shorter one (21" long). This is shown in Figure 13 for a subsonic jet and for a supersonic screeching jet. The plots show the spectral directivity as a function of polar angle and frequency. The color on the plot surface corresponds to the difference in the sound as measured with the two lengths of biplane (long minus short). As seen by the almost completely green surface $(-0.5<\Delta \mathrm{PSD}<$ $0.5)$ the biplane length did not make a significant difference for the subsonic jet. For the supersonic jet the biplane length modified the screech tones, and the longer biplane enhanced the downstream mixing noise. The modification to the screech tone will be explored shortly, but the increase in mixing noise with biplane length seems more likely to be due to changes in the jet flow, not pure acoustic propagation.

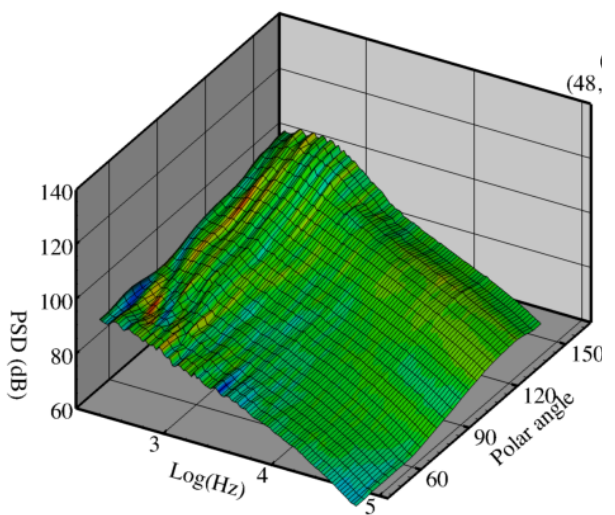

(a)

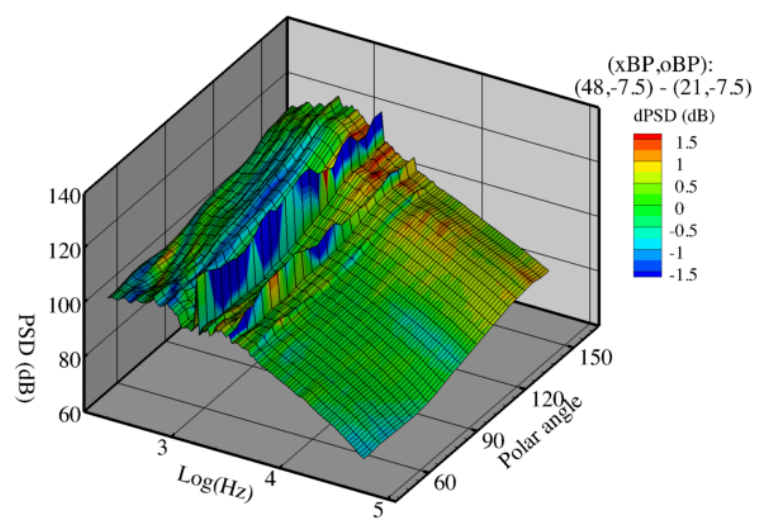

(b)

Figure 13 Spectral directivity of far-field sound, colored by difference (in dB) in sound, long (48”) biplane minus short (21"), both with max overlap (7.5"). Unheated M=0.98 flow (left) and unheated $M=1.4$ flow (right).

Next, consider the impact of the overlap between the biplane surface and the actuated surface (Figure 14). For the subsonic jet there is no significant impact of the overlap; however, there is significant impact on the noise from the supersonic jet. Not only is the screech tone impacted, but also a significant portion of the spectral directivity often associated with broadband shock noise. Surprisingly, the large red region indicates that more BBSN was measured with the overlapped case. 


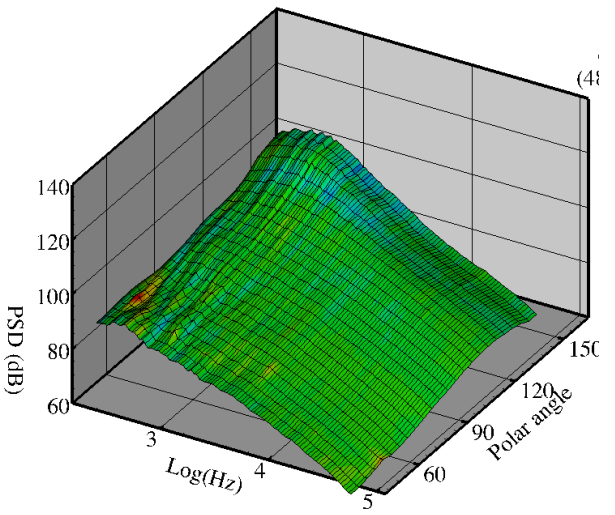

(a)

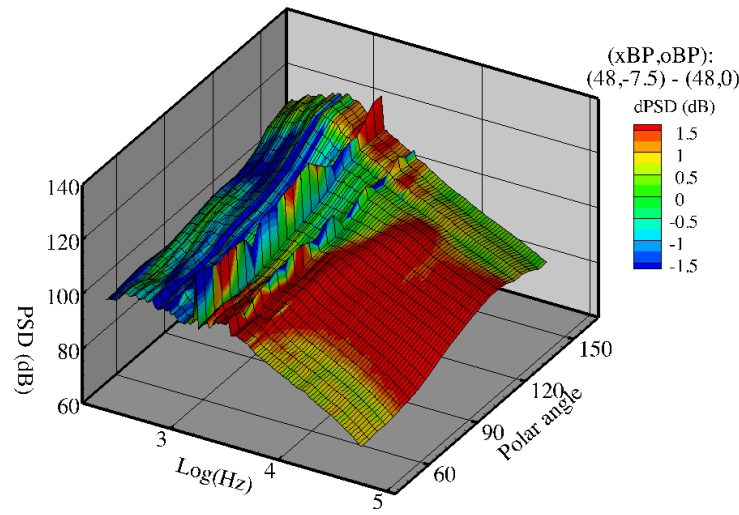

(b)

Figure 14 Spectral directivity of far-field sound, colored by difference (in $d B$ ) in sound between long biplanes with and without overlap (overlap minus no overlap). $M=0.98$ flow ( $a$ ) and $M=1.4$ flow (b), both unheated.

The phased array provides insight into the sensitivity of biplane size and placement for the supersonic jet cases. First, consider that the screech tone is highly directed along the jet axis, both up- and down-stream. When the upstream-going wave hits the nozzle it is strongly reflected outward to the phased array as is evident in the top image of Figure 15 which shows the sound source distribution for the shocked jet when the short biplane was deployed with overlap. Being very coherent, multiple leakage/diffraction points around the surface cause interference patterns which explains the positive and negative changes of the tonal directivity with plate dimensions observed in Figure 14.

The strong impact of the overlap is understood by comparing the source location maps of the short biplane with and without overlap, the top two images in Figure 15. With overlap (15a) the strongest source of the tone is the reflection off the rig upstream of the surface; relatively little sound is diffracted through the gap between the surfaces. However, as the overlap was minimized (15b), sound reflecting from the nozzle went through the gap between the biplane and actuated surfaces, and scattered from the crossbar that held the upstream edge of the actuated plate. This became a very strong source for the tone frequency; note the higher colorbar scale on this image (120 dB vs. $115 \mathrm{~dB} \max$ levels).

It is also possible that the variation in the gap may have changed the screech behavior of the jet, and in turn the broadband shock noise: the gap seems to be associated with a strong $\quad(>1.5 \mathrm{~dB})$ increase in broadband
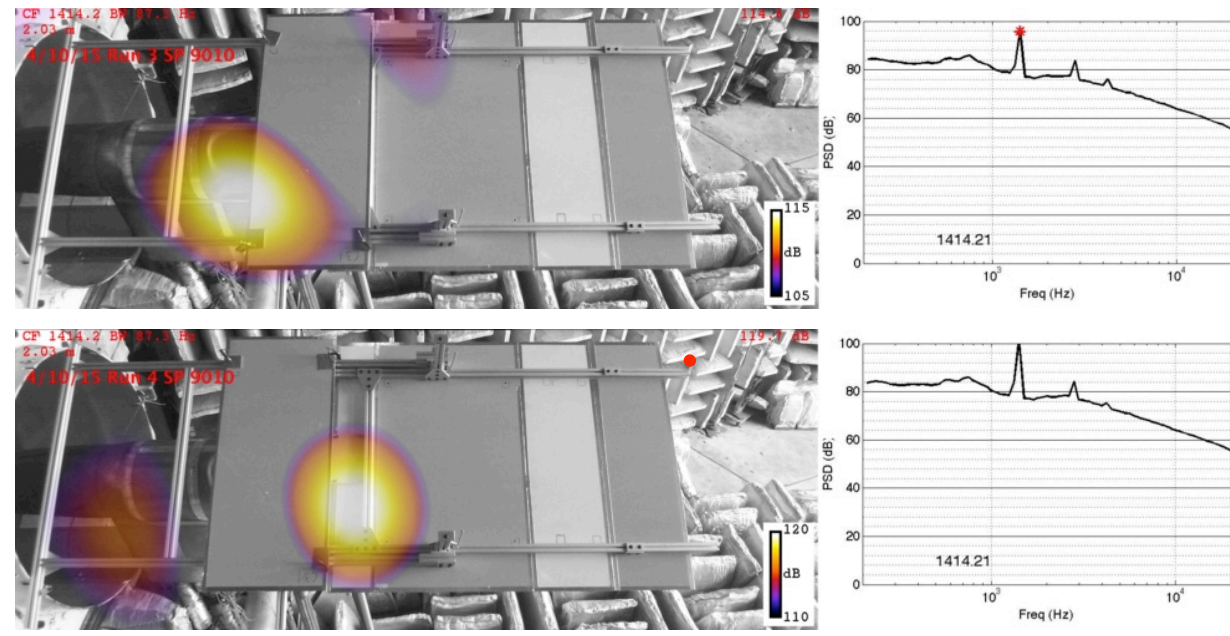

(a)
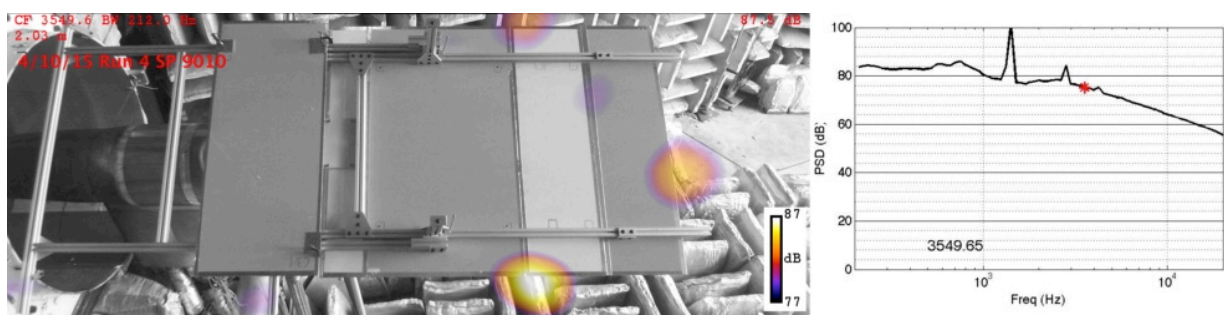

(b)

Figure 15 Source maps for screeching jet as captured by phased array for short biplane on unheated core stream at $M=1.4$. In (a) biplane has 7.5" overlap over actuated surface; in (b),(c) biplane has zero overlap. In (b screech tone is strongly reflecting through gap. In (c) broadband shock noise is leaking around sides of actuated surface. Note difference in color bar scales. Red dot on spectra indicate frequency of sound maps. 
shock noise seen in Figure 14. The phased array sees significant leakage around the sides of the actuated surface for these frequencies (15c). The amount of overlap between the biplane and actuated surfaces not only made a significant difference for the screech tones, but also the broadband noise sources. The length of the biplane also made a difference on the tones and the broadband shock noise, primarily because these sources, being strongly directed upstream, reflected off the rig to the far-field observer without the biplane.

In contrast, the shielding by the biplane was hardly required for the subsonic cases. When the biplane was removed altogether and compared with the longest biplane (Figure 16) only a few frequencies showed increased sound levels, and those mostly at far upstream angles around $10 \mathrm{kHz}$. When the phased array was used to image this frequency the source distribution showed that this extraneous sound was associated with sound reflecting from the rig, and especially the crossbars of the supports, upstream of the actuated surface. The discrepancy was in the range of 1 to $2 \mathrm{~dB}$ at the farthest forward angles. If the crossbars were not present it is doubtful that there would be any discrepancy between the far-field acoustics with and without the biplane surface.

The cumulative experience from looking over the many configurations and flows leads to a few general observations: Subsonic jet flows are generally easy to shield. Extra shielding surfaces are only needed to cover the upstream of the nozzle where there are reflecting surfaces directing the sound toward the microphones. Or put another way, diffraction around the leading edge of the plate is small compared to reflections from solid surfaces such as the external surface of the jet rig and supports for the actuated surface. Shock-containing jets are much more difficult, partly because screech tones are strongly directed upstream and partly because the details of the surface seem to heavily influence the screech behavior and the broadband shock noise.

That said, the subsequent test program with the actuated flat plate, although involving only subsonic flows, was done with the long biplane to be conservative. However, when the LM1044 planform model was tested, the biplane was omitted and the phased array was used to check for sound sources/reflections not located in the flow (none were found).

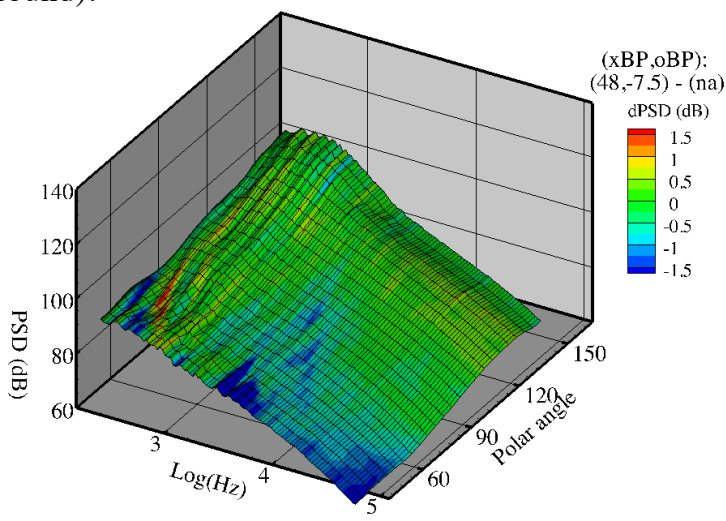

(a)

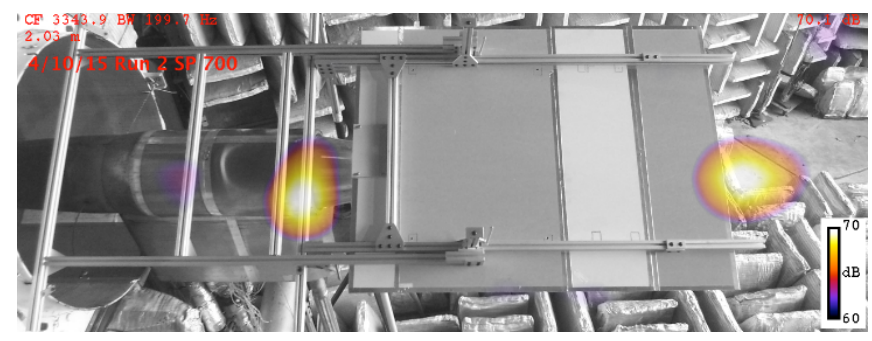

(b)

Figure 16 Unheated, $M=0.98$ jet. (a): Spectral directivity of far-field sound, colored by difference (in $d B$ ) in sound between long biplane with overlap and no biplane (with biplane minus without); $(b)$ : source map at frequency of maximum discrepancy $(3.3 \mathrm{kHz})$ showing noise reflecting off rig to be the source of discrepancy.

\section{B. Sample JSI data for separate flow nozzles near flat surfaces}

A test matrix involving twelve conditions, two nozzles, five surface lengths, and five standoffs was acquired to expand the JSI database to include separate flow, dual stream nozzles. In this paper a sample of this database is presented. An in-depth analysis is equating the flows to equivalent single-stream jets. ${ }^{9}$

First, differences in far-field sound (with surface minus without the surface) are presented for a selection of cycle points run on one nozzle geometry. Figure 18 shows carpet plots of acoustic spectral directivity with colors denoting the acoustic difference caused by the presence of a short $\left(x_{E} / D e=2.2\right)$ actuated surface set on the bypass lip (standoff $h_{E}=0$ ") for a low subsonic jet, a high subsonic jet, and a supersonic jet. Based on experience with simple singlestream jets, one can identify the increase in noise (red) at low frequencies and broadside angles with the dipole produced by the large-scale structures passing over the surface's trailing edge. One can also identify the shielding (blue) of high frequencies. The trailing edge dipole becomes very weak relative to the jet mixing noise as the jet speed is increased, due to the $U^{6}$ scaling of the dipole relative to the $U^{8}$ scaling of the mixing noise. Not quite as obvious is the reason for the directivity of the shielding. As expected, it is fairly uniform across polar angle for the low subsonic jet, but is highly directional (stronger 'shielding' in aft angles) for the high-speed jets. As the low 
frequency mixing noise sources are not blocked from a downstream observer most likely the difference is caused by changes to the mixing noise sources in the presence of the surface.

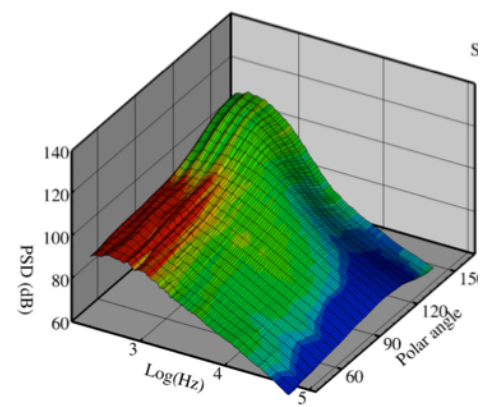

(a)

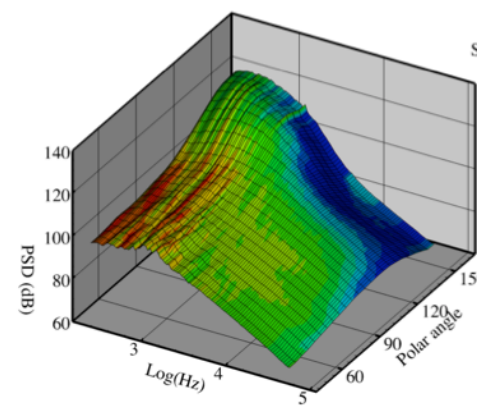

(b)

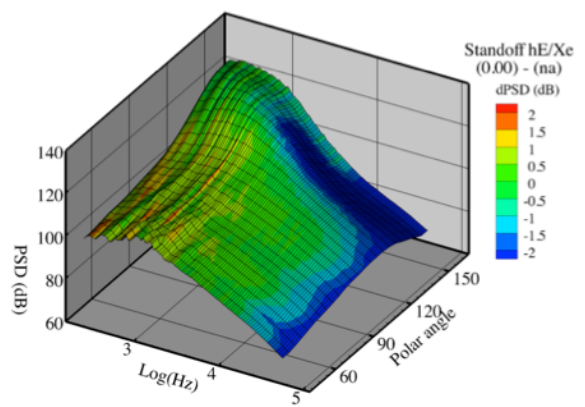

(c)

Figure 18 Sample spectral directivities for various dual-stream jets, color showing acoustic impact of surface (with surface minus without) for length $x_{E} /$ De $=2.2$, standoff $h_{E}=0$ ". Setpoints (a) 1312, (b) 1815, and (c) 2120 .

Now consider the impact of changing geometries for a given nozzle and flow condition. Figure 17 shows a matrix of plots for the far-field impact of surfaces with combinations of different lengths (across the row) and different standoffs (down the columns), all for the low subsonic jet flow of setpoint 1312. Again relating to the single-stream simple nozzle results, the dipole is seen to be strong for all cases where $h_{E} / x_{E}$ is small. For a given standoff the dipole strength increases as the surface is lengthened, and for a given length is weakened by increases in standoff distance. The dipole is negligible when the standoff is increased to 4.1" for the short surface.

Interestingly, the shielding (blue region) is nearly the same for all surface configurations, removing only the
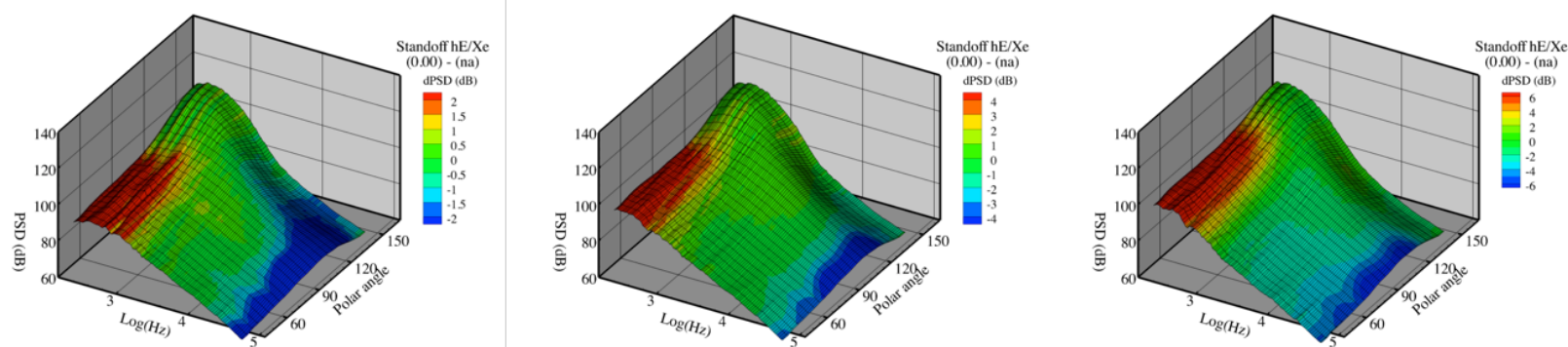

$$
h_{E}=0.0 ”, x_{E} / D_{e}=2.2
$$

$$
h_{E}=0.0 ", x_{E} / D_{e}=4.2
$$
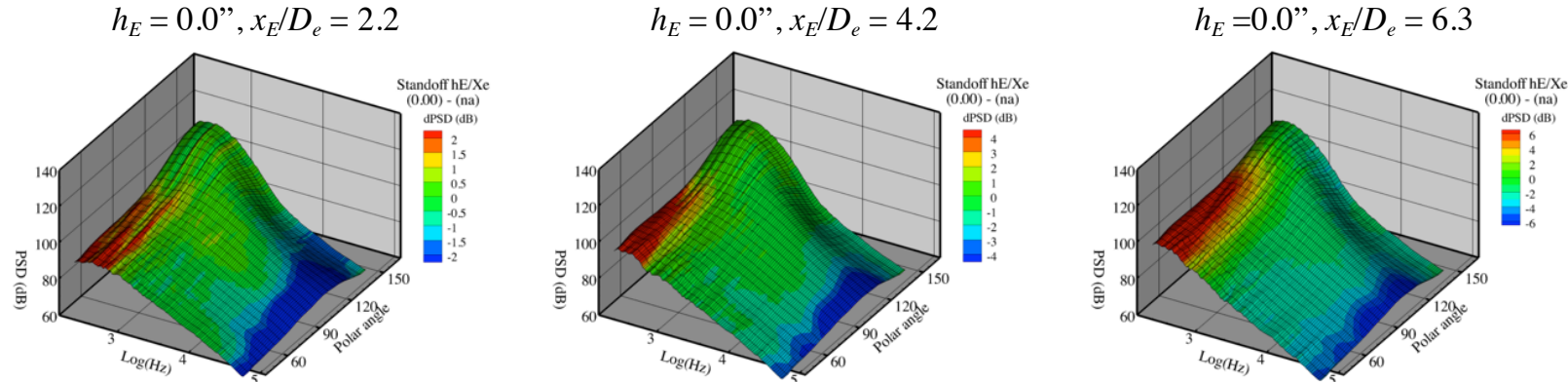

$$
h_{E}=1.6 ”, x_{E} / D_{e}=2.2
$$
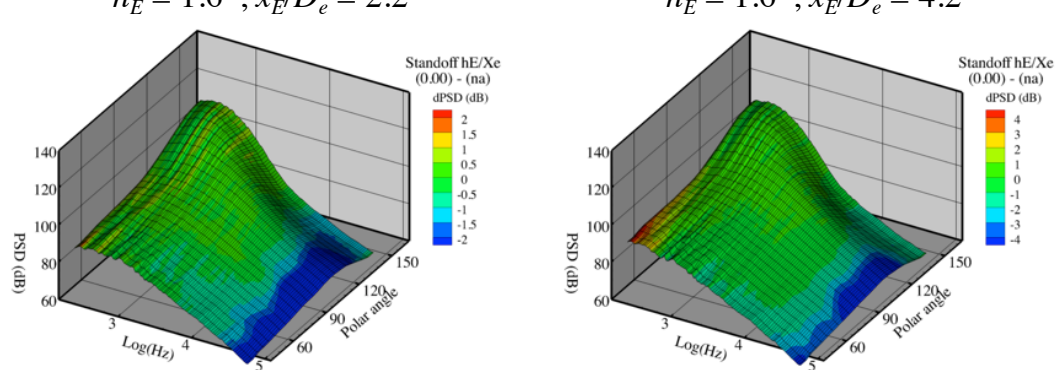

$h_{E}=4.1 ", x_{E} / D_{e}=2.2$

$h_{E}=4.1 ", x_{E} / D_{e}=4.2$

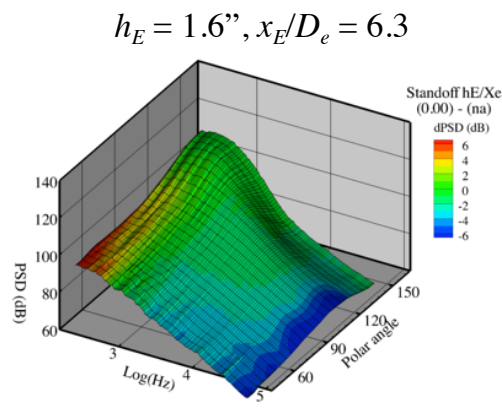

$h_{E}=4.1 ", x_{E} / D_{e}=6.3$

Figure 17 Sample spectral directivities for dual-stream jet at setpoint 1312, color showing acoustic impact of surface (with surface minus without). 
highest frequencies. The axial source distribution of dual-stream jet plumes effectively have two major source regions, one well downstream of the potential core producing most frequencies, and one at the nozzle exit producing only the highest frequencies. This is in contrast with simple (one stream and no plug) single-stream jet flows that have a peak source location that continuously shifts downstream with decrease in frequency ${ }^{8}$. Figure 19a presents normalized distributions of peak source location as a function of frequency for the single-stream (obtained with either only the core flow on, or both the core and bypass set the same to mimic a single stream jet) and dual-stream jets tested in this test. By defining the axial coordinate to start at the upstream-most nozzle exit $x_{0}$, and normalizing by the calculated potential core length, the single-stream data collapses to a smooth curve that runs from the end of the potential core at $S t_{D e}=0.3$ to effectively the nozzle exit by $S t_{D e}=5$. The data shows considerable scatter at $S t_{D e}$ above 1 in this dataset, possibly because of the impact of the external plug; earlier data without a plug did not show this scatter ${ }^{8}$.

The peak source location plots for the dual stream jets, Figure 19b, did not follow the smooth trend of the singles-stream jets. The potential core used in normalizing this data was computed using the fully mixed flow parameters, and this has provided a reasonable collapse of the data from the various flows. However, the sources are significantly shifted downstream relative to the simple single-stream jets (black line). Second, the peak location is a region just downstream of the potential core for a wide range of frequencies before shifting abruptly to the nozzle exit for the highest frequencies.

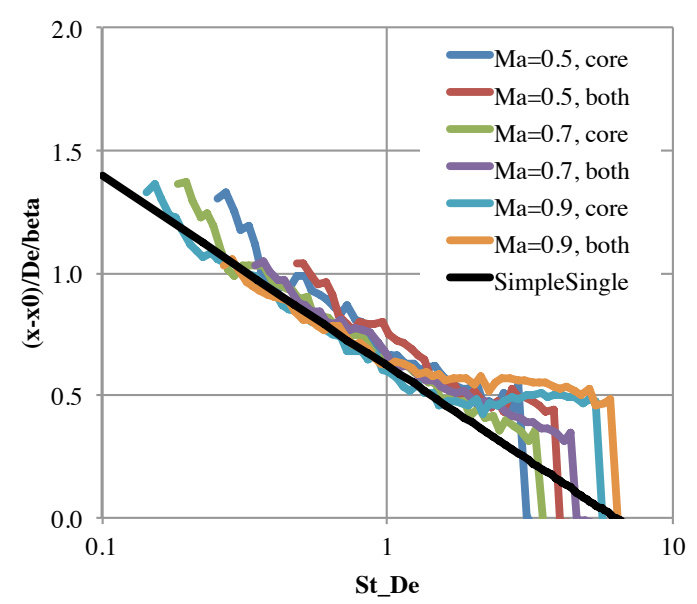

(a)

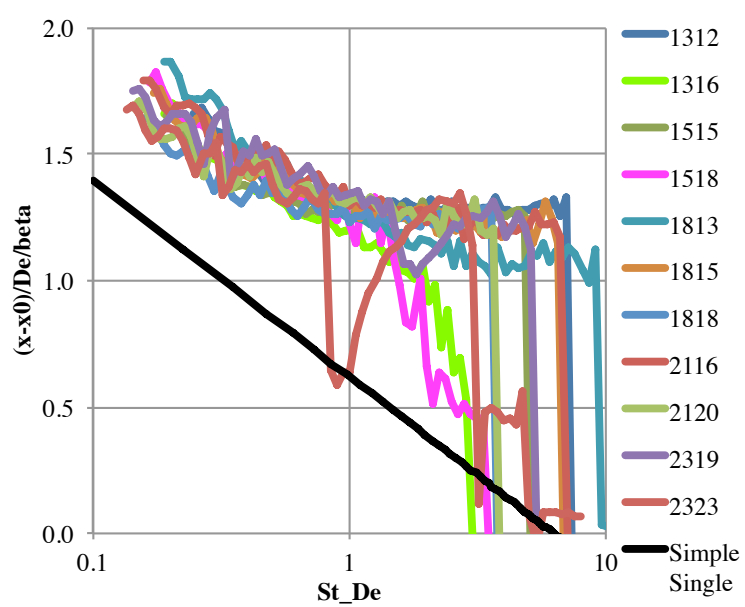

(b)

Figure 19 Axial location of peak source strength (as measured by phased array) vs frequency for (a) singlestream flows and (b) dual-stream flows. Axial location normalized by calculated potential core length (beta), equivalent diameter $D_{e}$, and shifted origin $x_{0}$.

This sudden shift in source location with frequency was also found in the case of the inverted velocity profile nozzle. Figure 20 presents the measured source distribution for one flow condition, showing how the source distribution slowly moves toward the nozzle with increasing frequency until it becomes bimodal at $5 \mathrm{kHz}$, with one small source region developing around the plug in addition to the main source region several diameters downstream. At higher frequencies the source region at the nozzle is over $10 \mathrm{~dB}$ greater than the downstream source region.

This difference in source distributions will likely require that the JSI shielding models derived for a simple single-stream jet be revised for multi-stream jets. Being able to predict the sudden shift in peak location with frequency will be key to this modeling and needs more investigation. 

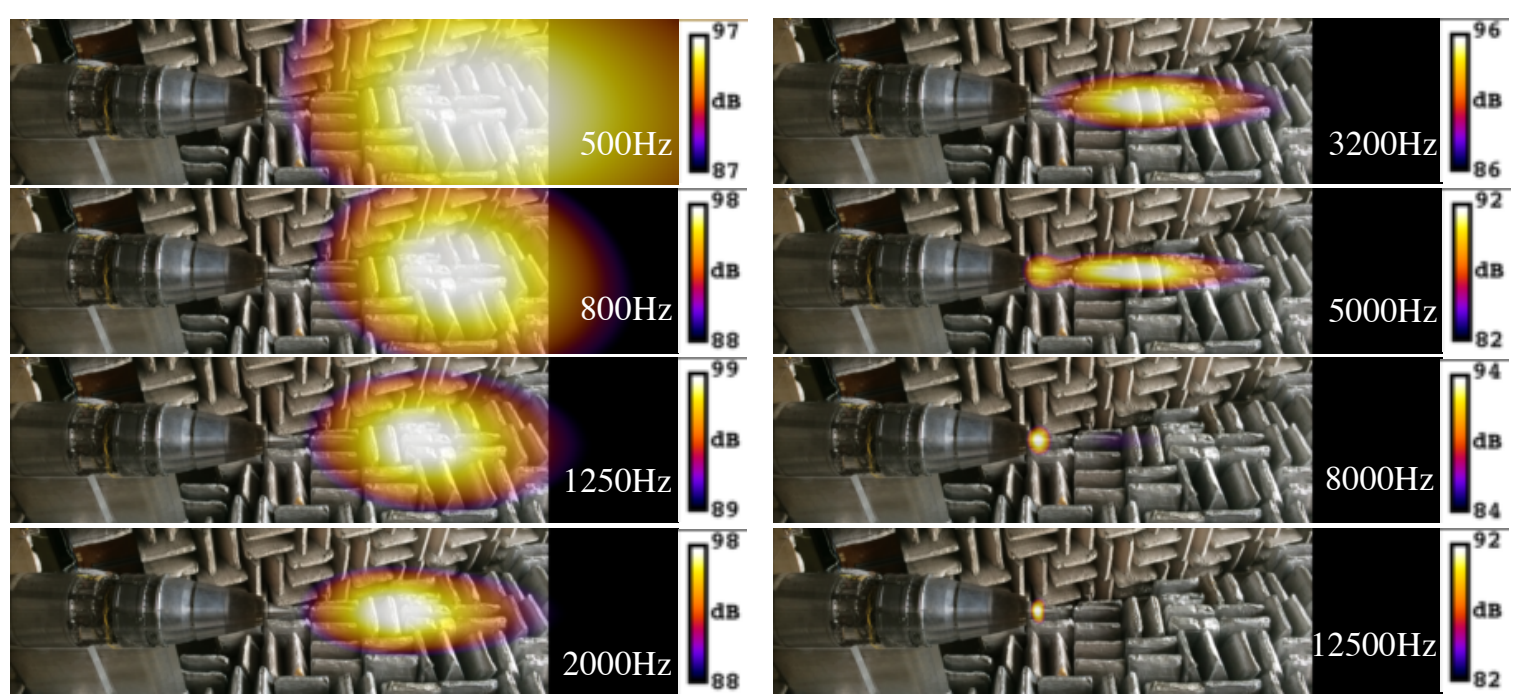

Figure 20 Sound source maps produced by the phased array and overlaid on the array's field of view for a range of frequencies. Inverted velocity profile nozzle at setpoint 3350.

\section{Simulation of installed propulsion on LM $1044 \mathrm{~N}+2$ Supersonic Vehicle}

Turning now to the tests using the JSI 1044 configuration, the simulated aircraft planform, first consider the impacts of installation of the center engine for both a sideline and a community observer, and then the impacts of the outboard engines.

\section{JSI 1044 center engine configuration}

Because the central engine is top-mounted, the acoustic impact is first one of shielding to an observer on the ground, with the addition of a trailing edge dipole. The pylon, which supports the nacelle above the surface, is relatively short and by the end of the aft deck, which is 2.4 nozzle diameters downstream of the nozzle lip, the trailing edge is only slightly further from the centerline than the nozzle lip, the pylon surface being at an angle of $1.5^{\circ}$ from the jet centerline. Refer to Figure 10, keeping in mind that the observers (microphones) are in the ceiling in AAPL.

The acoustic impact of the installation is shown in Figure 21 using the same format as above, with the surface shape corresponding to the measured spectral directivity of the installed propulsion system noise and the color conveying the difference made by the installation (installed propulsion system minus bare nozzle). The trailing edge dipole (red region) is very notable at an observer angle normal to the aft deck (left plot), but is reduced somewhat at an azimuthal angle of $60^{\circ}$, consistent with a dipole directivity. Shielding (green/blue regions) is significant across a wide range of frequencies and polar angles for both observers. When the sound is scaled up to full scale (10:1), the dipole will shift to frequencies low enough to minimize perceived noise levels, while the shielding will favorably impact frequencies where annoyance is higher.

Source

distributions measured by the phased array for the LM1044 central engine configuration are shown for the bare nozzle and for the two observer azimuthal angles in Figure 22.

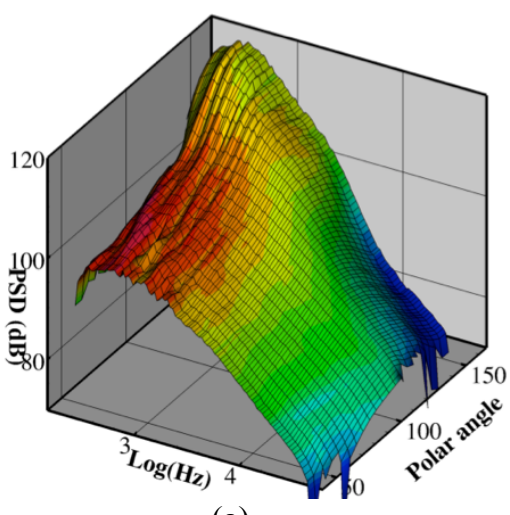

(a)

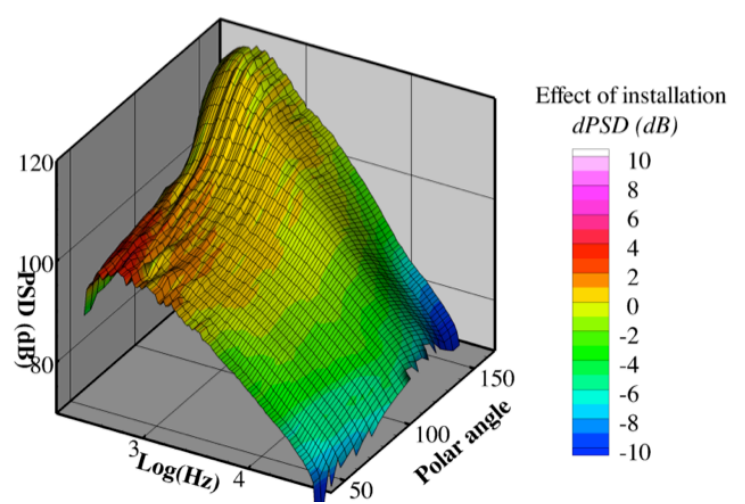

(b)

Figure 21 Spectral directivities for inverted velocity profile nozzle installed in central engine position, color showing acoustic impact of installation (installed minus bare jet) for community observer (a) and sideline observer (b). Setpoint 3350. 
The frequency, $12.5 \mathrm{kHz}$, was selected because this frequency is at the lower end of the frequencies that show significant shielding by the aft body, and at a frequency which the phased array produces clean results. Note that the colorbar scales are not the same, especially for the bare nozzle source map. In the upper left plot, the source distribution for the bare nozzle, down to a relative source strength of $80 \mathrm{~dB}$, is located upstream of the plug tip. To measure the source strength of the plume further downstream, say aft of the location where the aft deck covers the plume, the source distribution upstream was eliminated and the colorbar scale adjusted (Figure 22b). Simplistically, if the effect of the aft deck is simply to acoustically shield the mixing noise source using ray acoustics, this is what should be observed when the aft deck is added. When the aft deck configuration is measured (Figure 22c,d), the source distribution is found to be significantly larger with peak source density roughly $2 \mathrm{db}$ louder. (At this frequency the uncovered source strength is essentially the same for both azimuthal observers.)

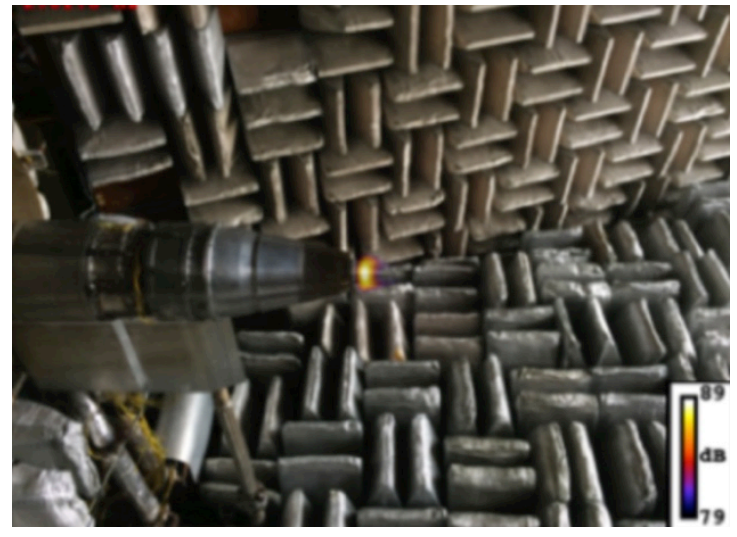

(a)

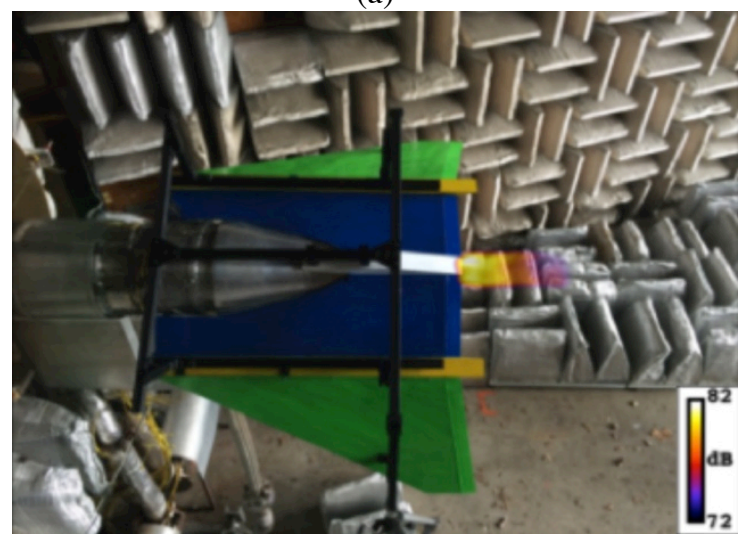

(c)

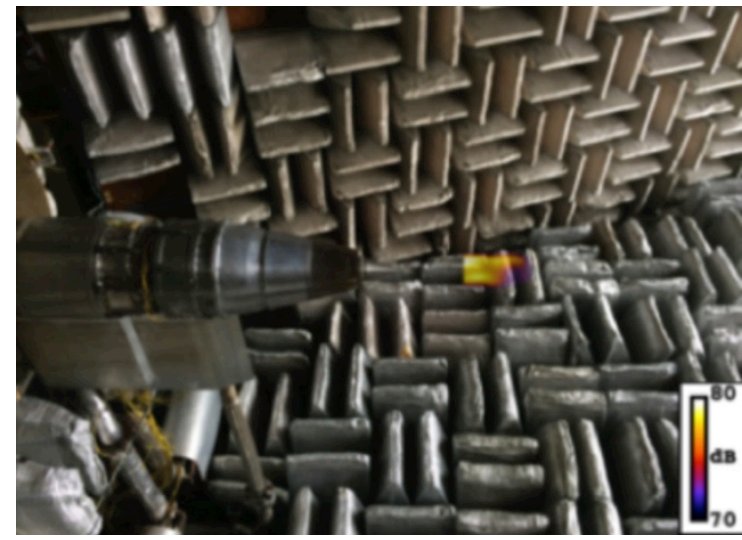

(b)

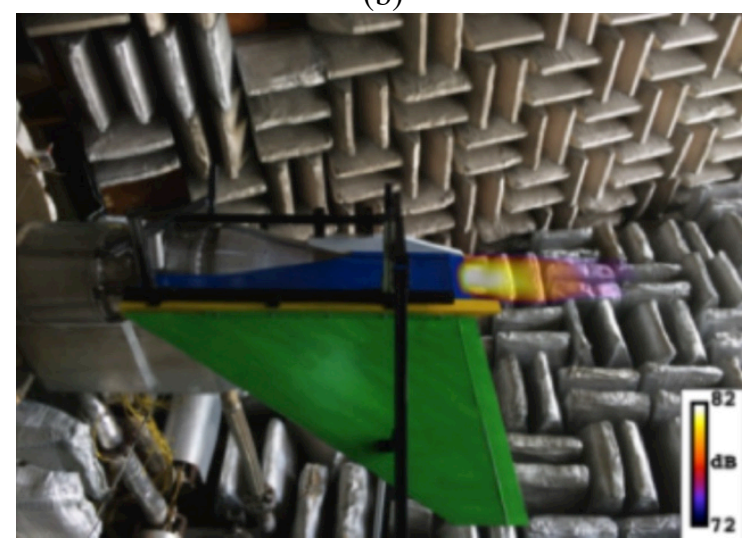

(d)

Figure 22 Sound source maps produced by the phased array and overlaid on the array's field of view. Four views of the center engine configuration are shown for a given frequency of $12.5 \mathrm{kHz}$ : (a) uninstalled nozzle, $(b)$ uninstalled but processed only for region not covered by planform, $(c)$ community observer $\left(0^{\circ}\right)$, (d) sideline observer $\left(60^{\circ}\right)$. Inverted velocity profile nozzle at setpoint 3350.

The increased source strength downstream of the aft deck edge is likely caused by changes to the turbulence of the plume cause by the presence of the aft deck. In PIV studies ${ }^{11}$ of simple jets on surfaces it was observed that when a round jet is very near the surface a second shear layer is initiated at the trailing edge of the surface. This additional turbulence may be the source of the added source strength. Hence, a shielding model that assumes the source distribution is not affected by the surface and uses ray acoustics to estimate the amount of noise blocked by the surface will overestimate the amount of noise reduction obtained by shielding.

\section{JSI 1044 outboard engine configuration}

Consider next the effect of installation on the outboard engines, located under the aft deck (shown above in Figure 11). Here the noise is being reflected by the underside of the aft deck and possibly by the tailfin to the sideline observer. The outboard engines are suspended from the aft deck at the junction of the aft deck and the tail fin on a long pylon. The geometry is such that only about half of the plume is exposed to a trailing edge, but the trailing edge is almost 4 nozzle diameters downstream and not far from the lipline of the nozzle. Note that three 
azimuthal angles must be considered for this installation as the sideline observer sees a near-side engine and a farside engine. Thus azimuthal angles of $-60^{\circ}, 0^{\circ}$, and $+60^{\circ}$ were measured.

As expected, the installation increases the far-field noise, partly due to the trailing edge dipole and partly due to reflection of the mixing noise. In Figure 23 the trailing edge dipole is seen to be very strong at $0^{\circ}$ and $-60^{\circ}$. It is not quite as strong toward the far-side sideline observer at $+60^{\circ}$ because this observer is nearly in the plane of the aft deck and therefore in the null plane of the dipole. There is a significant reflection to the community observer at $0^{\circ}$, especially in the forward arc, but not as much for the $-60^{\circ}$ sideline observer.

The biggest surprise is the increase in high frequency noise to the far-side $\left(+60^{\circ}\right)$ sideline observer. The geometry is such that the observer is nearly in the plane of the aft deck, and hence there is very little surface in the proper orientation to reflect the source to the observer. Also, given that the spectral character of the increase is somewhat isolated to a given range of frequencies above $10 \mathrm{kHz}$ it seems likely that this is not due to simple reflection, which must mirror the spectral character of the source for relatively large flat hard surfaces. Instead, it is postulated that an additional, highly directional, source may be created by the presence of the pylon, which sticks up above the aft deck. Energy from the turbulent shear layer may be scattered by the pylon edge, much in the same manner as occurs at the trailing edge of the surface, to produce a directional dipole oriented along the aft deck.

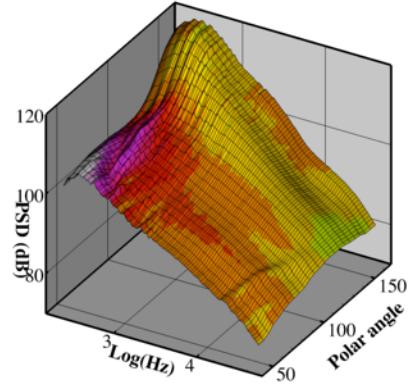

(a)

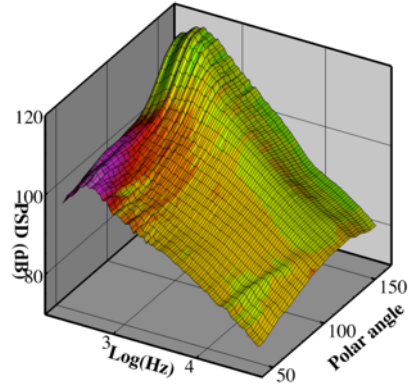

(b)

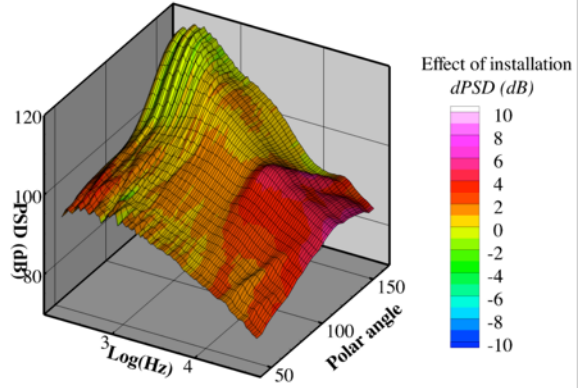

(c)

Figure 23 Spectral directivities for inverted velocity profile nozzle installed in outboard engine position, color showing acoustic impact of installation (installed minus bare jet) for (a) community observer $\left(0^{\circ}\right)$, (b) nearside sideline observer $\left(+60^{\circ}\right)$, and (c) far-side sideline observer $\left(-60^{\circ}\right)$. Setpoint 3360 .

The phased array was again used to give insight into the far-field observations. Source maps for the three observation angles plus the bare nozzle are shown in Figure 24. At $12.5 \mathrm{kHz}$, near the peak of the extra noise to the $60^{\circ}$ observer, the bare nozzle is producing noise mostly at the nozzle lip. There is a slight (5dB down) source that extends along the plug and about one diameter downstream of the plug tip. When the surface is installed, the source at the tip of the plug is strengthened.

It is not clear how the presence of the surface increases the source strength at the end of the plug. The community $0^{\circ}$ observer (Figure 24b) sees a reflection of the source near the nozzle in the aft deck, and careful study of the source map for the $-60^{\circ}$ observer (Figure 24d) shows that the source distribution is slightly skewed, indicating a reflection largely behind, but slightly offset from the primary mixing noise source. Looking at the source distribution observed at the $+60^{\circ}$ orientation (Figure 24c) does not show significantly different distribution from the other observer angles. This was surprising because this is the angle where the large increase was seen at this frequency, postulated above to be due to a new source. One possible explanation is that the phased array is actually positioned at a slightly different azimuthal location than the far-field array, its angle being slightly below the plane of the aft deck. If a dipole were preset on the pylon edge, essentially on the aft deck surface, perhaps the aft deck is blocking it from the phased array. 


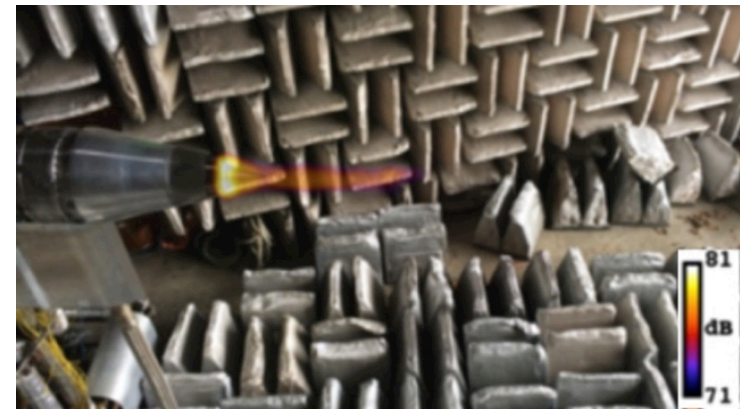

(a)

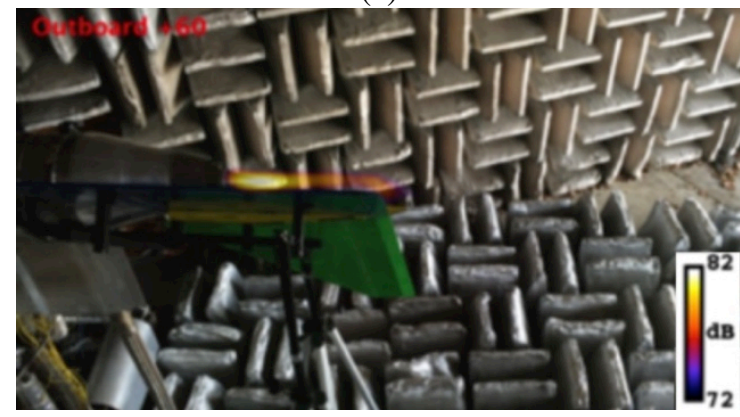

(c)

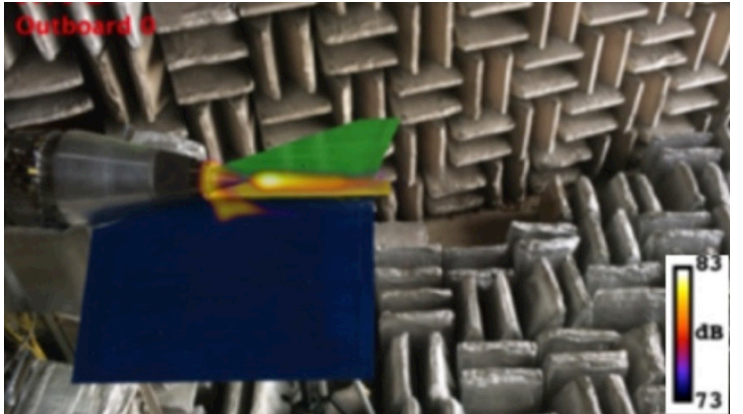

(b)

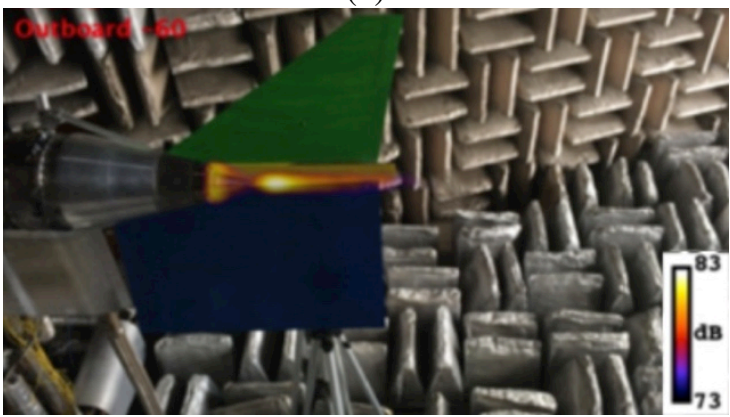

(d)

Figure 24 Sound source maps produced by the phased array and overlaid on the array's field of view. Four views of the outboard engine configuration are shown for a given frequency of $12.5 \mathrm{kHz}$; (a) uninstalled nozzle, $(b)$ community observer $\left(0^{\circ}\right)$, (c) far-side sideline observer $\left(+60^{\circ}\right)$, and (d) near-side sideline observer $\left(-60^{\circ}\right)$. Inverted velocity profile nozzle at setpoint 3360 .

\section{Overall impact of propulsion installation}

Having looked at the details of how noise is impacted when the nozzle is installed on the realistic airframe of the LM1044 aircraft, consider now the impact on the certification metric, Effective Perceived Noise Level (EPNL). This metric, which takes into account sound amplitude, frequency response of humans, and duration of the exposure, is used to certify aircraft and determine if airport noise goals can be met. When the scale-model far-field data was (1) transformed to full scale, (2) transformed to the proper distance from the observer for a representative 1000' level flight at Mach 0.3, (3) corrected for atmospheric effects for a standard day, and (4) processed as per FAR36 regulations, we call it a 'component EPNL'. This is a rough approximation of the noise impact of the total airplane, but it is one part of the overall assessment of the aircraft noise and a good metric for assessing the impact of installation on the dominant noise component of the total aircraft noise at takeoff.

A chart of EPNL for three cycle points around the expected takeoff engine setting is shown in Figure 25. Each line in the chart is one combination of engine installation and observer angle. Also included in the figure is the noise of the isolated nozzle to serve as a baseline to see the impacts of the installation. From the figure it is observed that the central engine benefits from the installation by $2-3 \mathrm{EPNdB}$. Recall from Figure 21 that the central engine installation produced a $2-4 \mathrm{~dB}$ increase in noise from the trailing edge dipole at very low frequencies while providing $2-4 \mathrm{~dB}$ of shielding at higher frequencies where humans are responsive. Clearly, the large dipole made little difference in the EPNL given that the scale factor of roughly 10:1 shifts the frequency of the trailing edge dipole down to under $100 \mathrm{~Hz}$.

The outboard engine configurations all produce an increase in EPNL, but the increase is very modest $(\sim 1 \mathrm{EPNdB})$ for all but the far-side sideline observer $\left(-60^{\circ}\right)$. The increase in noise at high frequencies impacts the perceived noise levels for this observer to an increase in EPNL of $3-4 \mathrm{EPNdB}$. Referring to Figure 23, the trailing edge dipole, of frequency less than $1 \mathrm{kHz}$ at modelscale, is very much reduced at the $-60^{\circ}$ observer angle compared to the other azimuthal angles. However, noise at frequencies between 10 and $30 \mathrm{kHz}$ are greatly increased relative to the other observers, and make a big difference in the EPNL. This increased noise has such a strong azimuthal dependence that it will be difficult to predict, but will be important to get right for the particular trajectory the aircraft ultimately flies during takeoff.

Finally, adding the spectral directivities of all three engines with their various configurations and comparing this to the uninstalled case for the sideline cycle point demonstrates the entire impact of installation. For the installed case, spectra from one shielded center engine and two reflecting outboard engines, near- and far-side, were summed to simulate the spectral directivity at the sideline observer point. The effective perceived noise level was $6.0 \mathrm{EPNdB}$ 
above that computed for the noise of the single uninstalled engine. For comparison, three uninstalled engines produce 4.8 EPNdB greater noise than a single uninstalled engine. The shielding on one center engine was less the reflection of the two outboard engines, producing a 1.2 EPNdB increase in noise that is attributable to installation effects.

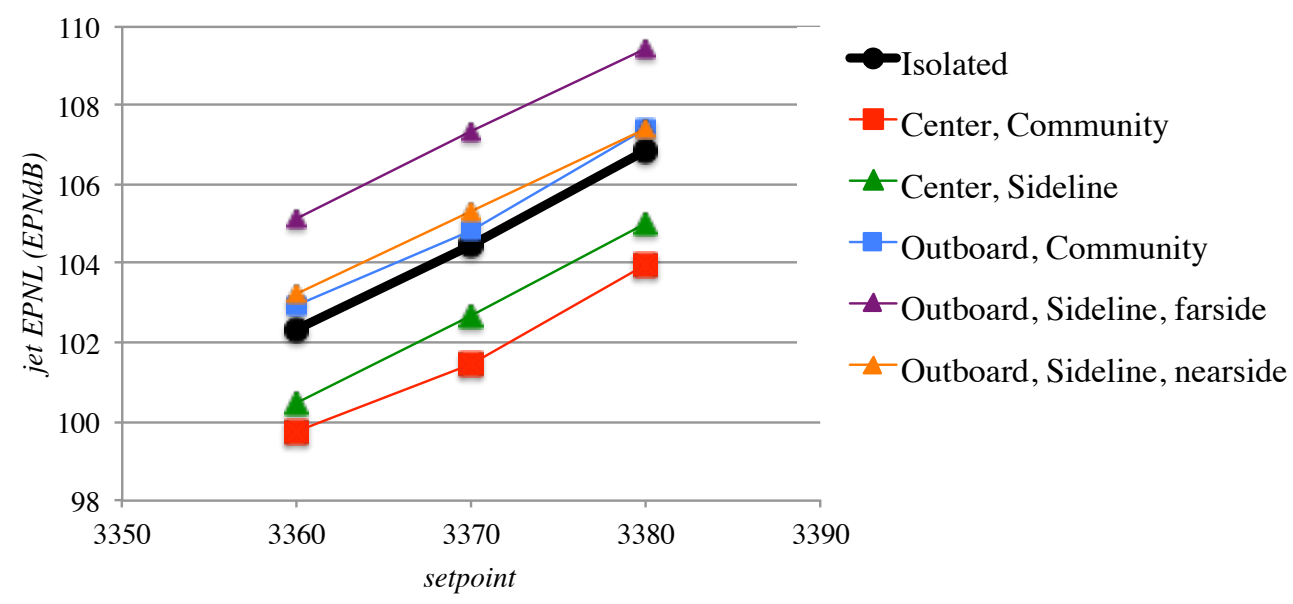

Figure 25 Jet component EPNL for isolated propulsion and as installed on LM1044 for combinations of engine installation location and certification observer over a range of engine cycle points near takeoff power.

\section{Summary}

Tests to further understand and predict the acoustic impacts of jet-surface interaction (JSI) have been described. The overall objective of the test was to prepare for a 2016 test validating the design of a low-noise, low-boom supersonic commercial airliner. Design requirements are investigated for a partial aircraft planform for subscale testing, especially focusing on the amount of shielding surface that must be provided to simulate the acoustic environment between the propulsion exhaust system and the observer. It was found that, in the absence of shockcontaining jets with their upstream-directed noise sources, there was little need for an extensive shielding surface upstream of the nozzle. A 'biplane' concept, allowing a separate surface to cleanly extend the shielding upstream without careful fitting of the surface to the contours of the jet rig, was viable in cases where upstream noise was a problem. Above all, these tests demonstrated the value of using a phased array to confirm that noise was emanating from uncovered regions in the jet plume and not from regions supposed to be covered by the aircraft body.

To provide data for more extensive modeling of JSI effects single-stream jet flows were tested to connect the current dataset with those measured previously in more simple tests. The JSI database was extended to include dualstream jets, with both conventional and inverted velocity profiles. Because the source distribution in dual-stream jets is not as monotonically varying with frequency the model for jet shielding and reflection will be different for dual stream jets. The measured source distributions shown here to collapse on a common curve when properly normalized, give guidance to this modeling.

Finally, we have given initial measurements of the installation impacts of integrating the propulsion on the airframe for a supersonic vehicle with simulated airframe planform and nozzles, including estimates of the impact on perceived noise levels for the exhaust noise. These measurements show that for engines integrated on the topside of the craft suppressions in the range of $1-2 \mathrm{EPNdB}$ are expected. For engines integrated under the wing, well forward of the trailing edge of an aft deck, the reflections from the body can add $2-4$ EPNdB to the uninstalled jet noise.

\section{Acknowledgements}

The Commercial Supersonics Technology Project under the NASA Advanced Air Vehicles Program supported this work. Many thanks for Dennis Huff and Rick Bozak for their careful manuscript reviews.

${ }^{1}$ Brown, Clifford A. "Jet-surface interaction test: far-field noise results." Journal of Engineering for Gas Turbines and Power 135.7 (2013).

${ }^{2}$ Brown, C., "An Empirical Jet-Surface Interaction Noise Model with Temperature and Nozzle Aspect Ratio Effects", AIAA 2015-0229, (2015).

American Institute of Aeronautics and Astronautics 
${ }^{3}$ Brown, C., "Empirical Models for the Shielding and Reflection of Jet Mixing Noise by a Surface", AIAA 2015$3128,(2015)$.

${ }^{4}$ Doty, M.J., Brooks, T.F., Burley, C.L., Bahr, C.J., and Pope, D.S. "Jet Noise Shielding Provided by a Hybrid Wing Body Aircraft", AIAA 2014-2625 (2014).

${ }^{5}$ Doty, M.J., "Investigation of Twin Jet Aeroacoustic Properties near a Hybrid Wing-Body Shield," AIAA $J$ 52:10, (2014).

${ }^{6}$ Morgenstern, J., et al. "Advanced Concept Studies for Supersonic Commercial Transports Entering Service in the 2018-2020 Period Phase 2." NASA CR-2015-218719 (2015).

${ }^{7}$ Bridges, J, "Simple Scaling Of Multi-Stream Jet Plumes For Aeroacoustic Modeling", AIAA 2016-1637, (2016).

${ }^{8}$ Podboy, G.G., "Jet-Surface Interaction Test: Phased Array Noise Source Localization Results", ASME GT2012-69801, (2012).

${ }^{9}$ Brown, C.A., Podboy, G.G. \& Bridges, J., "Modeling Jet-Surface Interaction Noise for Separate Flow Nozzles," $22^{\text {nd }}$ CEAS/AIAA Aeroacoustics Conference, Lyon (to be presented May 2016).

${ }^{10}$ Henderson, Brenda S., and Leib, Stewart J., "Three-stream jet noise measurements and predictions." The Journal of the Acoustical Society of America 136.4 (2014).

${ }^{11}$ Brown, C.A. \& Wernet, M.P. "Jet-Surface Interaction Test: Flow Measurement Results", AIAA 2014-3198, (2014). 